\title{
On "sluicing" with apparent massive pied-piping
}

\author{
Klaus Abels ${ }^{1}$
}

Received: 15 June 2017 / Accepted: 3 July 2018 / Published online: 28 November 2018

(C) The Author(s) 2018

\begin{abstract}
This paper provides the first detailed description of a type of elliptical $w h$ question first noted in a footnote in Ross's seminal paper on sluicing. Under certain, very restricted circumstances, sluicing appears to be able to tolerate $w h$-phrases with massive pied-piping. I propose to analyze this pattern in terms of (recursive) contrastive left-dislocation accompanied by clausal ellipsis. While it has long been known that contrastive left-dislocation can be recursive, the particular ellipsis pattern observed here has not been described in detail before. The proposed analysis capitalizes on the striking distributional similarities between the apparent sluicing pattern and the pattern of clausal ellipsis with contrastive left-dislocation. At a theoretical level, the paper provides a defense of $w h$-move-and-delete approaches to sluicing by removing Ross's nagging counterexample to the generalization that only $w h$-movable constituents can be sluicing remnants.
\end{abstract}

Keywords Ellipsis · Sluicing · In-situ theory of ellipsis · Contrastive left-dislocation · German · English · Move-and-delete theory of ellipsis

\section{Introduction}

In his seminal paper on sluicing, Ross (1969) observed a curious three-way interaction between pied-piping, ellipsis, and word order. The pattern is illustrated in (1):

(1) a. He has a picture of somebody, but [a picture of who] I don't know.

b. *He has a picture of somebody, but [a picture of who] he has I don't know.

c. *He has a picture of somebody, but I don't know a picture of who.

d. *He has a picture of somebody, but I don't know [a picture of who] he has.

K. Abels

k.abels@ucl.ac.uk

1 Department of Linguistics, UCL, 2 Wakefield Street, London, WC1N 1PF, UK 
e. He has a picture of somebody, but who I don't know.

f. He has a picture of somebody, but who he has a picture of I don't know.

g. He has a picture of somebody, but I don't know who.

h. He has a picture of somebody, but I don't know who he has a picture of.

The pattern can be summarized as follows: When an indirect question appears in its canonical position ((1c), (1d), (1g), and (1h)), massive pied-piping in the sense of Heck (2008) and Cable (2010) is prohibited independently of ellipsis. However, when the question is fronted, the pied-piping behavior of full and elliptical questions becomes dissociated; elliptical questions now allow (1a) but full questions still disallow (1b) massive pied-piping. These facts are schematized in (2).

(2) Interaction:

\begin{tabular}{cc|cc|cc|}
\multirow{2}{*}{} & \multicolumn{3}{|c|}{ Pied-piping } \\
& & & \multicolumn{2}{|c|}{ regular } & massive \\
\cline { 3 - 6 } & & \multicolumn{2}{|c|}{ ellipsis } & \multicolumn{2}{c|}{ ellipsis } \\
\multirow{2}{*}{ fronting } & yes & no & yes & no \\
\hline & $\checkmark$ & $\checkmark$ & $\checkmark$ & $*$ \\
& no & $\checkmark$ & $\checkmark$ & $*$ & $*$ \\
\hline
\end{tabular}

In the footnote containing example (1a) (Ross 1969:281 fn. 10 ) Ross tacitly assumes that (1a) is derived from the ungrammatical (1b) by sluicing. Under this analysis, the sentence furnishes a counterexample to the otherwise extremely strong generalization that sluicing obeys constraints on pied-piping. This generalization in turn forms the strongest argument Ross has for the assumption that wh-movement feeds sluicing. The existence of counterexamples threatens the argument from pied-piping. Consequently, the theory built to explain the generalization is threatened. This explains the exasperation in the text of Ross's footnote where he professes to being "totally baffled by such sentences which may well totally invalidate" the argument from pied-piping for the wh-move-and-delete analysis of sluicing.

The descriptive aim of the present paper is to investigate sentences like (1a) in detail. Analytically, I propose to reject the idea that sluicing is involved in their derivation and offer an alternative. While this is a modest proposal, the present analysis of Ross's example constitutes a defense of $w h$-move-and-delete approaches to sluicing against, on the one hand, direct interpretation approaches that posit no contextually variable structure at the ellipsis site and against, on the other hand, Abe's (2015) in-situ approach. It is these consequences that make the quirky example worth our sustained attention.

Before proceeding it will be useful to introduce some terminology explicitly. Ross (1969) established the term sluicing for elliptical indirect questions where the $w h$ phrase stands for the entire question. A typical example is given in (3).

$$
\begin{gathered}
\text { [John bought }[\text { a car }]] \text { but I don't know }[[\text { which one }] \\
{[\text { correlate }]}
\end{gathered}
$$


The embedded question is understood to mean which one John bought, although what is pronounced is only which one. I will refer to the pronounced wh-phrase as the remnant. The category of the remnant in (3) is DP. The sluice is made up of the remnant and the ellipsis site. In (3) the ellipsis site is marked by an underscore. The sluice itself is a clause, a CP (see Ross 1969; Levin 1982; Merchant 2001; Culicover and Jackendoff 2005). Therefore, the category of the sluice is crucially dissociated from the category of the remnant. Further, the semantic content of the sluice depends on a different clause given in the context. This clause will here be called the antecedent. In canonical examples (Chung et al.'s 1995 merger type of sluicing), the antecedent contains an indefinite whose identity is queried by the sluice. This indefinite is known in the literature as the correlate. ${ }^{1}$

While Ross restricted the term sluicing to indirect questions, the subsequent literature agrees that there are also examples of sluicing in root clauses. In particular Bechhofer (1976), Hankamer (1977), Merchant (2001), Lasnik (2005) all assume that examples like (4) must involve sluicing since it shows inversion of the preposition and its complement (swiping), a property that is characteristic of sluicing and shows up under no other elliptical process.

\section{A: Joe was talking.}

B: Who to?

However, the existence of root sluicing does not preclude the possibility that elliptical matrix questions might be derived by processes distinct from sluicing (see Bechhofer 1976; Hankamer 1977 and below).

The approaches to sluicing under discussion in the main body of this paper all assume that there is syntactic structure at the ellipsis site and that it varies from context to context. I will use the term 'pre-elliptical structure' generically for such syntactic structure and 'pre-sluice' (following Dayal and Schwarzschild 2010) when referring to sluicing specifically. Plausible pre-sluices for (3) include the following:

a. ... which one he bought.

b. ....which one it is.

Finally, we need a name for the construction type exemplified by Ross's example. Abe (2015) calls it "topicalized sluicing," which is descriptive of his analysis but misleading if I am correct. In line with the analysis proposed in the present paper, I will use the term "Sluicing" With Apparent Massive Pied-piping construction or swamp construction for short. Sluicing is set in scare quotes, because, as we will see, example (1a) does not involve sluicing. Also, the example only appears to involve pied-piping. While the acronym is thus similar to the names given to subtypes of sluicing (sprouting, swiping, spading), the absence of an -ing suffix reflects that the swamp construction is not a subtype of sluicing.

\footnotetext{
${ }^{1}$ When there is no overt correlate, the construction type is called sprouting (Chung et al. 1995), (ia), and when correlate and remnant contrast, I will follow Merchant's (2001) terminology and call such examples contrast sluicing, (ib).
}

(i) a. He ate, but I don't know what.

b. He ate two potatoes, but I don't know how many eggs. 
With these preliminaries out of the way, let us return to Ross's example. Ross (1969) introduces example (1a) at the end of a section containing the generalization that possible sluicing remnants are possible occupants of Spec, $\mathrm{CP}$ in full whquestions and impossible sluicing remnants are impossible occupants of Spec,CP in full $w h$-questions. While the pied-piping violation in (1a) might seem mild to some speakers, the following paradigm (based on Abe 2015:48, ex. (7)-(8)) makes the problem even clearer. Pied-piping of doing by what is impossible in all indirect, nonelliptical questions and becomes possible only when the indirect question is both fronted and elliptical, (6a).

(6) a. He spent the entire day doing something at the mall, but doing what I don't know.

b. *He spent the entire day doing something at the mall, but [doing what] he spent it, I don't know.

c. *He spent the entire day doing something at the mall, but I don't know doing what.

d. *He spent the entire day doing something at the mall, but I don't know [doing what] he spent it.

e. He spent the entire day doing something at the mall, but what I don't know.

f. He spent the entire day doing something at the mall, but what he spent the entire day at the mall doing I don't know.

g. He spent the entire day doing something at the mall, but I don't know what.

h. He spent the entire day doing something at the mall, but I don't know what he spent the entire day at the mall doing.

I take the appearance of pied-piping that exceeds the bounds of what is usually possible in full questions to be characteristic of (unambiguous instances of) the swamp construction. Thus, Ross's and Abe's examples are unambiguous instances of the swamp construction while (1e) and (6e) are presumably ambiguous between a construal as a sluice and a swamp structure.

Ross (1969) flags the problem raised by example (1a) without solving it. The diagnosis of the problem under Ross's theory is obvious: The pre-sluice has to be syntactically isomorphic to the antecedent (identical up to $w h$-movement of the remnant) but the isomorphic pre-sluice is not well-formed, because of the pied-piping violation.

The issue carries over to the modern descendants of Ross's wh-move-and-delete analyses pioneered by Merchant (2001). Accounts following Merchant (2001) do not require syntactic identity between antecedent and pre-sluice but require semantic or pragmatic identity instead. The non-syntactic definition of ellipsis identity allows certain mismatches in pied-piping behavior between an isomorphic pre-sluice and the actual sluice (and its pre-sluice). For example, left-branch extraction is not allowed in English. Attributive adjectives require pied-piping of the DP $(7 \mathrm{~b}, \mathrm{~d})$. Sluicing on the other hand is compatible with apparent left-branch violations (7a). This pied-piping mismatch is problematic under Ross's approach but has a relatively straightforward resolution under a Merchant-style approach, since one can posit (8) as the pre-sluice for (7a) (see Barros et al. 2013, 2014; Montali 2014; Abels 2018 for arguments in favor of this move). 
(7) a. I met a very tall man, but I am not going to tell you how tall.

b. *I met a very tall man, but I am not going to tell you how tall I met a man.

c. I met a very tall man, but I am not going to tell you how tall a man exactly.

d. I met a very tall man, but I am not going to tell you how tall a man exactly I met.

(8) [how tall] he is

Likewise, while the complement of a prepositions requires pied-piping of the preposition in most languages, there are now many examples that flout this pied-piping requirement under sluicing. The general fact is illustrated by the Brazilian Portuguese example in (9). Again, such examples are very clearly problematic for Ross's theory because the putative pre-sluice is ill-formed. They are easier to handle under the approaches inspired by Merchant; thus, Rodrigues et al. (2009) posit something along the lines of who it is as the pre-sluice for $(9 \mathrm{~b}) .^{2}$

Brazilian Portuguese from Rodrigues et al. (2009:177 ex. (5))

a. *Quem que a Maria dançou com? who that the Maria danced with intended: 'Who did Maria dance with?'

b. A Maria dançou com alguém, mas eu não sei quem. the Maria danced with someone but I not know who 'Maria danced with someone, but I don't know who.'

Although the more modern approaches thus leave some room for maneuver in the face of pied-piping mismatches between isomorphic pre-sluices and actual sluices, the modern theories still predict that Ross's generalization should hold: possible sluicing remnants are possible occupants of Spec, $\mathrm{CP}$ in full wh-questions (though not necessarily in wh-questions isomorphic to the antecedent) and impossible occupants of Spec,CP in full wh-questions are impossible sluicing remnants. Because of this, allowing non-isomorphic pre-sluices will not help with the problem posed by (1a) and (6a). There are no well-formed pre-sluices corresponding to these examples; massive pied-piping is always ruled out in indirect questions in English. Notice that there are good reasons not to extend the wiggle-room for pied-piping mismatches further: The task is to explain why Ross's example, (1a), is acceptable while not sacrificing the explanation of why elliptical questions in situ do not allow massive pied-piping, (1c).

Tweaking ellipsis identity thus does not seem to get us closer to an understanding of the three-way interaction found with the swamp construction. Another initially promising avenue might be the idea that movement within the ellipsis site has special properties. There is a long tradition of analyses that posit special properties of movement in the ellipsis site. A special island-repair property is commonly invoked in the

\footnotetext{
${ }^{2}$ This is not the place to decide what the correct analysis of apparent P-stranding under sluicing is. See Merchant (2001), Fortin (2007), Stjepanović (2008), Stjepanović (2012), Rodrigues et al. (2009), van Craenenbroeck (2010), Algryani (2010, 2012), Sato (2011), Nykiel (2013, 2017), Leung (2014), Philippova (2014), Alshaalan (2015), Alshaalan and Abels (2018), Kim (2015), Albukhari (2016), Molimpakis (2016), Abels (2017a) among others for discussion.
} 
literature (Ross 1969; Lakoff 1970; Chomsky 1972; Merchant 2001, 2008; Lasnik 2001; Fox and Lasnik 2003; Hornstein et al. 2007; Müller 2011; Bošković 2011). We might then be tempted to connect the more liberal pied-piping possibilities found in (1a) and (6a) to such special properties of movement in the ellipsis site. While it is not clear how islands might be relevant to Ross's example, the idea that covert movement might be made overt by ellipsis seems more directly relevant (see Johnson 2001: Abels 2012; Manetta 2013; Ortega-Santos et al. 2014; Thoms 2014; Weir 2014; Boone 2015; Gribanova and Manetta 2016; Abels and Dayal 2017; Shen 2018 for relevant proposals and discussion). Covert movement might be relevant because Kotek and Erlewine (2016) argue that the kind of pied-piping we find in (1a) is standard under covert movement. We might then be able to explain the status of (1a) by appealing to the idea that ellipsis allows covert movement to be made overt. In a precurser to the present paper (Abels 2017b), I pursued this idea. However, this line of thinking immediately runs into two problems: First, if sluicing allows covert movement to happen overtly, why does (1c) remain stubbornly ungrammatical? Second, if (1a) simply involved covert movement made overt by ellipsis, we should expect pied-piping in the swamp construction to track what is known about covert piedpiping. Kotek and Erlewine (2016) show that VPs behave differently from DPs when it comes to covert pied-piping; thus, we would wrongly expect (1a) and (6a) to behave differently. Invoking special properties of movement in the ellipsis site thus is not a promising avenue to pursue either.

The approach I adopt here starts by questioning Ross's assumptions about the preelliptical structure for (1a) and the process deriving ellipsis. Ross assumed tacitly that the pre-elliptical structure for (1a) is (1b) and that (1a) is derived from its preelliptical structure by sluicing. As we will see, both published accounts of the swamp construction (Bechhofer 1976; Abe 2015) reject at least one of these assumptions. Abe (2015) invokes sluicing but posits a very different pre-sluice. Bechhofer (1976) rejects both assumptions. The present account follows Bechhofer in rejecting both assumptions. If the present analysis is accepted, the generalization that sluicing remnants are systematically phrases that can appear in Spec,CP in $w h$-questions stands without counterexample. The case for an analysis in terms of $w h$-movement feeding ellipsis is correspondingly strengthened.

To foreshadow the analysis to be proposed, I will suggest that the swamp construction involves recursive contrastive left-dislocation accompanied by clausal ellipsis.

The background to the analysis is provided by two facts about German. First, German shows the swamp construction as well. That is, we find in German the same characteristic three-way interaction between pied-piping, fronting, and clausal ellipsis that we find in English. German examples showing this characteristic interaction have the same distribution and the same reconstructive properties as their English counterparts. Clearly, the German and the English examples should be analyzed the same way. Second, descriptively, German possesses another construction with the same distribution and reconstructive behavior as the swamp construction. I will call this construction contrastive left-dislocation with clausal ellipsis. Given the similarities between the swamp construction and contrastive left-dislocation with clausal ellipsis, both should be given the same analysis. By transitivity, we conclude that the swamp construction in English is an example of contrastive left-dislocation with clausal ellipsis. 
There are two superficial differences between the swamp construction and contrastive left-dislocation with clausal ellipsis: In the swamp construction but not in regular contrastive left-dislocation the left-dislocated element contains a $w h$-word. In the swamp construction but not in regular contrastive left-dislocation ellipsis is obligatory. I will relate these two important differences to each other.

I will now briefly illustrate that German also exhibits the swamp construction and give an example of recursive contrastive left-dislocation with ellipsis. This will be followed by a brief introduction of the analysis to be pursued in the rest of the paper.

The first set of examples below establishes the existence of sentences that show the characteristic interaction between pied-piping, fronting, and ellipsis in German. Example (10) reproduces the crucial part of Ross's paradigm, (1), and example (11) reproduces the corresponding part of Abe's paradigm, (6). When it comes to (11), the interaction is clear and obvious for all speakers I have consulted. The rendition of (10) requires comment. All speakers I have consulted judge the elliptical version of (10a) to be acceptable; the remaining three examples are subject to substantial but correlated variation. Most speakers that I have consulted (myself and two anonymous reviewers included) do not judge (10b) or the full version of (10a) as particularly deviant. ${ }^{3}$ For speakers who do find a substantial degradation in the in-situ and the full versions of (10), the elliptical version of (10a) exemplifies the swamp construction unambiguously. ${ }^{4}$

(10) Er hat eine Zeichnung von jemandem, aber

he has a drawing of somebody but

a. ... eine Zeichnung von wem (\% er hat), das weiss ich nicht.

a drawing of who he has dPR know I not

b. \%... ich weiss nicht, eine Zeichnung von wem (er hat).

I know not a drawing of who he has

'He has a drawing of somebody, but a drawing of who I don't know.'

(11) Er war heute den ganzen Tag im Einkaufszentrum, um dort he was today the entire day at.the mall in.order there etwas zu erledigen, aber

something to deal.with but

\footnotetext{
${ }^{3}$ This is somewhat surprising. The literature on pied-piping in German (see e.g. Webelhuth 1992; Heck 2008) claims that German has constraints on pied-piping that closely mirror those found in English and pied-piping of the type exemplified in (10b) is given as uniformly ungrammatical in that literature.

${ }^{4}$ For the more restrictive speakers of German, the elliptical version of (10a) is an unambiguous example of the swamp construction while for the more permissive speakers it also has a parse as a fronted sluice (and ellipsis remains optional for these speakers). This is fully parallel to the situation that obtains in the elliptical version of (1e), which is ambiguous in the same way.
}

The elliptical version (11a) is an unambiguous instance of the swamp construction for all speakers. 
a. ... um dort was zu erledigen (*er im Einkaufszentrum war), in.order there what to deal.with he in.the mall was das weiss ich nicht.

that know I not

b. *... ich weiss nicht, um dort was zu erledigen (er im

I know not in.order there what to deal.with he in.the Einkaufszentrum war). mall was

'He was the entire day at the mall today in order to deal with something but in order to deal with what, I don't know.'

Modulo these differences in pied-piping, the German swamp construction and its English counterparts have the same distribution and reconstructive properties. The relevant data establishing full parallelism between the English and the German swamp constructions is not given in the body of the text to save space. These data are given in Appendix A.

We now move on to contrastive left-dislocation with clausal ellipsis. Canonical examples of contrastive left-dislocation involve a left peripheral phrase, the left dislocate, which is followed by a V2 clause whose first element is a pronominal element resuming and agreeing in case and phi-features with the left dislocate. Because of its morphology, this pronoun is called a d-pronoun and will be glossed as dPR. In (12), the left dislocate is den Hans and the d-pronoun is den. The finite verb (have) follows the d-pronoun, producing a V3 surface pattern.

$$
\begin{aligned}
& \text { Den Hans, den habe ich gesehen. } \\
& \text { the.M.SG.ACC Hans dPR.M.SG.ACC hve I seen } \\
& \text { 'Hans I have seen (him).' }
\end{aligned}
$$

Example (13a) illustrates that contrastive left-dislocation is allowed in wh-questions (see Sect. 4 for details). The non-elliptical version of example (13b) shows that this is possible also under root coordination with fronting of the question. The configuration in (13b) is broadly the same we find in Ross's example (1a): root coordination and fronting. Interestingly, clausal ellipsis of the left dislocated question wer den zuletzt gesehen hat is possible in this configuration leaving behind the embedded left dislocate den Jungen and the matrix das weiss ich nicht. As far as I know, this is a novel observation. (Ott (2014:294-295, ex. (63a) and (65)) presents very similar examples with elided declaratives.) Notice that ellipsis of the question in (13b) is not an instance of sluicing since the entire question including the wh-phrase disappears leaving behind just the left dislocate. The elliptical version of (13b) is what I call contrastive left-dislocation with clausal ellipsis. Section 4 shows that contrastive leftdislocation with clausal ellipsis has the same distribution and reconstructive behavior as the swamp construction.

$$
\begin{aligned}
& \text { a. Den Jungen, wer hat den zuletzt gesehen? } \\
& \text { the.M.SG.ACC boy(M) who has dPR.M.SG.ACC last seen } \\
& \text { 'The boy, who saw him last?' }
\end{aligned}
$$


b. Ich weiss, wer das Mädchen zuletzt gesehen hat, aber den

I know who the girl last seen has, but the.M.SG.ACC

Jungen, (wer den

zuletzt gesehen hat,) das

boy(M) who dPR.M.SG.ACC last seen hat dPR.N.SG.ACC

weiss ich nicht. ${ }^{5}$

know I not

'I know who last saw the girl, but the boy, who last saw him, (that)

I don't know.'

The analysis I propose for Ross's example (1a) capitalizes on the possibility of eliding the question in (13b) leaving behind the left dislocate. I suggest that a picture of who in Ross's example is a left dislocate and that it is left dislocation (not wh-movement) that allows what appears to be massive pied-piping in the swamp construction.

The structure for Ross's example (1a) under this analysis is given in diagrammatic from in (14). Here, I represent contrastive left-dislocation as movement to a dedicated projection (CLD-P). The movement originates in a phrase made up of the left-dislocate and the d-pronoun. ${ }^{6}$ Numerical subscripts in the tree are there only to individuate nodes for the purposes of discussion. Movement and binding relations are indicated with subscripted letters. The reader may, of course, feel free to assume the copy theory of movement. The d-pronoun in $\mathrm{Spec}, \mathrm{CP}_{1}$ is silent in English. I discuss this point below in Sect. 5 .

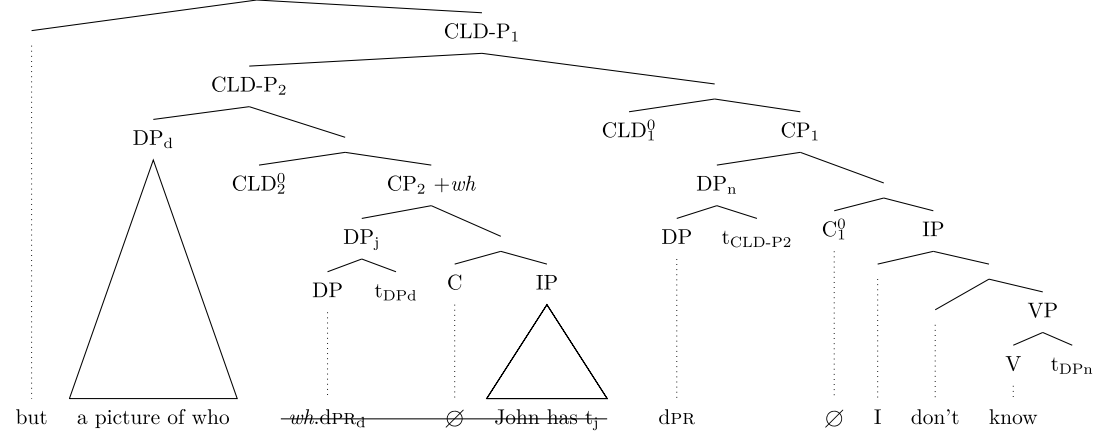

\footnotetext{
${ }^{5}$ The intonation in these examples recalls hanging-topic left-dislocation (see Altmann 1981; Frey 2004 for discussion of the construction variously called nominaitivus pendens, hanging-topic left-dislocation, or freies Thema). Section 4 below argues in detail that example (13b) involves contrastive left-dislocation rather than hanging-topic left-dislocation. The progredient intonation otherwise typical of contrastive leftdislocation is presumably disrupted by the gap at the ellipsis site or maybe by the clausal boundary at the ellipsis site's right edge. An anonymous reviewer points out that the d-pronoun in this examples must be stressed when the question is not elided. In view of the generalization that stressed material cannot generally be elided, this is a problem for the analysis proposed here.

${ }^{6}$ Nothing substantive in the analysis presented here changes if contrastive left-dislocation targets a CP adjoined position or if left dislocation is not analyzed in terms of movement at all. As discussed at the end of Sect. 4, nothing in this paper directly bears on the choice of analysis for contrastive left-dislocation. The reader is therefore invited to recast the structure in (14) in terms of their own favorite analysis of contrastive left-dislocation.
} 
CLD- $\mathrm{P}_{2}$ has the structure of (German style) contrastive left-dislocation: There is a left peripheral left dislocate resumed by a d-pronoun. The left dislocate from the question is the DP (a picture of who) containing the wh-word. $\mathrm{CP}_{2}$ is elided. Ellipsis is obligatory in case the left dislocate contains a wh-word. As shown below, structures like CLD- $\mathrm{P}_{2}$ can occur in root environments. In the structure diagrammed here, this contrastive left-dislocation structure $\left(\mathrm{CLD}-\mathrm{P}_{2}\right)$ is itself the left dislocate in a larger contrastive left-dislocation structure represented by CLD-P 1 . We thus have a recursive contrastive left-dislocation structure with obligatory clausal ellipsis of $\mathrm{CP}_{2}$ within the left dislocated clause. The elliptical process, which, as shown in (13b) is independently available, elides a full $\mathrm{CP}$ to the exclusion of the left dislocate. We are therefore not dealing with sluicing. Hence, if the current proposal is accepted, the threat for the $w h$-move-and-delete analysis of sluicing posed by the swamp construction dissolves.

The rest of the paper justifies these analytical choices and is structured as follows. Section 2 introduces the two previous published approaches to the swamp construction, empirically evaluates their predictions about its distribution, and extracts core structural claims from them. Section 3 is dedicated to empirically testing the structural claims emerging from the discussion in Sect. 2. The function of these sections is, on the one hand, to build up, for the first time, a systematic and detailed understanding of the distribution and other properties of the swamp construction and, on the other hand, to justify the need for a more descriptively adequate approach. Section 4 describes, for the first time in detail, the properties of left-dislocation with clausal ellipsis. The section compares the distribution and properties of the swamp construction with those of contrastive left-dislocation with question ellipsis and establishes a very strong match between the two. This section thus serves as the main justification for the current approach. In Sect. 5, I turn to two questions raised by the analysis: Why is ellipsis obligatory? And how can we apply the analysis to English? Section 6 concludes the body of the paper. There are two appendices. Appendix A provides additional data showing that the swamp construction in German both with verbal and with nominal remnants behaves essentially identically to the swamp construction in English on the one hand and to contrastive left-dislocation with clausal ellipsis on the other hand. Inclusion of these data in the main body of the text would have bloated the presentation but the data are necessary to complete the argument: The swamp construction in English should be analyzed the same way as the swamp construction in German because they have the same distribution and other properties; the swamp construction in German should be analyzed the same way as contrastive left-dislocation with clausal ellipsis because they have the same distribution and properties. Appendix B centers on the question of whether Abe's in-situ approach to sluicing derives the pied-piping generalization, the generalization that only $w h$-movable constituents can be sluicing remnants. The discussion shows that Abe's proposal does not derive this generalization and therefore fails to pose a serious challenge to $w h$-move-and-delete approaches to sluicing.

\section{Previous approaches to the swamp construction}

This section briefly summarizes the two published accounts of the swamp construction: Bechhofer (1976) and Abe (2015). We extract key claims from both accounts to 
be tested in Sect. 3 and evaluate the distributional predictions emerging from both accounts. In terms of distribution, Bechhofer's approach has a clear edge. Corresponding distributional data from the German swamp construction and from contrastive left-dislocation with question ellipsis can be found in Appendix A, examples (104)(111). These data support the parallel between the swamp construction in English, its German counterpart, and contrastive left-dislocation with question ellipsis.

\subsection{Bechhofer's (1976) parenthetical analysis}

Bechhofer (1976) assumes that the most important distributional characteristic of the swamp construction is that massive pied-piping is possible in elliptical direct questions, (15a) and (16a), but not in elliptical indirect questions, (1c) and (6c), nor in direct or indirect non-elliptical questions, (1d), (6d), (15b), and (16b).

A: He has a picture of somebody.

a. B: A picture of who?

b. $\mathrm{B}^{\prime}$ : *[A picture of who] does he have?

A: He spent the entire day doing something at the mall.

a. B: Doing what?

b. $\quad \mathrm{B}^{\prime}$ : *[Doing what] did he spend it (at the mall)?

The root cases above are the canonical cases of the swamp construction for Bechhofer. She assimilates Ross's example to the root case by invoking a process that promotes the embedded interrogative to root status, fronts it, and turns the apparent matrix (I don't know in Ross's example) into a parenthetical.

As far as the root case is concerned, Bechhofer analyzes it not as a type of sluicing but in terms of the same elliptical process underlying fragment answers. I will refer to this process as fragment formation. ${ }^{7}$ Bechhofer assumes that fragment formation (in English) is strictly a root phenomenon (see Temmerman 2013; Griffiths 2015 for discussion) and that it involves non-constituent ellipsis of an in-situ remnant (see Merchant 2004; Weir 2014; Shen 2018 for relevant discussion). Bechhofer's derivation for a simple fragment is illustrated in (17). The assumption that the remnant in the swamp construction is in situ explains why constraints on pied-piping may be flouted. The assumption that fragment formation is strictly a root phenomenon explains the distribution of the swamp construction.

Canonical fragment formation (question before declarative)

Q: What did John buy last night?

Decl: John bought a book last night.

$\rightsquigarrow$ fragment formation

Decl': John bought a book last night.

\footnotetext{
${ }^{7}$ Following Hankamer (1971:Sect. 4.4.5), Bechhofer calls this process stripping. But stripping is now established as a term for a (superficially) different process with a substantially different distribution. Stripping in the modern sense crucially involves coordination and, unlike fragments, is not restricted to roots and root-like contexts. To avoid confusion, I will use the term fragment formation for what Bechhofer calls stripping.
} 
Of course, fragment formation usually ${ }^{8}$ involves a wh-correlate and a non-whremnant, as well as an interrogative antecedent and a declarative elliptical clause, (17). Those relations are reversed under Bechhofer's analysis of the swamp construction, (18): The correlate is a non-wh-phrase and the remnant a $w h$-phrase; the antecedent is declarative and the elliptical clause interrogative. Under Bechhofer's analysis, examples like (18a) without massive pied-piping have two derivations: one as a sluice and one as a swamp structure. Examples like (15a) on the other hand only have the derivation as a swamp structure via fragment formation, (18b). The sluicing derivation is blocked, because constraints on pied-piping are violated.

a. Ambiguous: swamp type fragment/sluice

Decl: He has a picture of somebody.

$\mathrm{Q}_{1}$ : He has a picture of who?

$\rightsquigarrow$ fragment formation

$\mathrm{Q}_{1}$ : He has a picture of who?

$\mathrm{Q}_{2}$ : Who does he have a picture of?

$\rightsquigarrow$ sluicing

$\mathrm{Q}_{2}$ : Who does he have a picture of?

b. Unambiguous: swamp type fragment

Decl: He has a picture of somebody.

Q: He has a picture of who?

Q': He has a picture of who?

$\rightsquigarrow$ fragment formation

As noted, Bechhofer assumes that in fragment formation the remnant may remain in situ. This is allowed also in the swamp construction because, according to Bechhofer, fragment formation may be ordered before $w h$-movement. Subsequent $w h$-movement is then bled for reasons that remain somewhat unclear. ${ }^{9}$ This is how Bechhofer's analysis predicts that constraints on pied-piping should play no role in the swamp construction: the remnant never moves.

Bechhofer then turns to Ross's example, (1a). She points out that it involves root coordination. Indeed, she claims that the elliptical clause is the root of the second conjunct. The apparent matrix I don't know acts as a parenthetical, she suggests citing Hooper and Thompson (1973). Bechhofer's derivation is sketched in (19).

John has a picture of somebody,

a. ... but I don't know [he has a picture of who].

$\rightsquigarrow \mathrm{CP}$ fronting

b. ... but [ [he has a picture of who] I don't know]

$\rightsquigarrow$ matrix backgrounding

c. ... but [he has a picture of who] < parenthetical I don't know> fragment formation

d. ... but [he has a picture of who] $<$ parenthetical I don't know>

\footnotetext{
${ }^{8}$ Though not always (see Hankamer's Sect. 4.4.5 “Wrong," and Merchant 2004; Griffiths and Lipták 2014; Weir 2014 for recent discussion).

${ }^{9}$ Bechhofer (1976:54) speculates that $w h$-movement is suppressed following ellipsis because it is string vacuous. This rationalization of why fragment formation bleeds $w h$-movement is dubious, though: Whmovement of who after ellipsis in (18b) would not be string vacuous but result in the changed string who a picture of.
} 
We can extract two claims from Bechhofer's analysis. One claim concerns the distribution: Elliptical questions should be able to violate constraints on pied-piping only when they are roots, (15), or fronted under root coordination, (1a), and nowhere else. The second claim is that in non-root instances, the apparent matrix should behave as a parenthetical. This second claim will be evaluated in Sect. 3. Here we simply observe that Bechhofer correctly predicts the distribution of the swamp construction.

Bechhofer immediately predicts that Ross's example and Abe's example should work only when the disjunction occurs at the root but not when it is embedded. This prediction is tested in the examples below:
a. [1 The persistent reports [2 [that he has a picture of someone] but [(that) we don't know who (he has a picture of)] ] ] are disconcerting.
b. *[1 The persistent reports [2 [that he has a picture of someone] but [(that) we don't know a picture of who (he has)] ] ] are disconcerting.
c. $*[1$ The persistent reports [2 [that he has a picture of someone] but [(that) a picture of who (he has) we don't know] ] ] are disconcerting.
d. *[The fact [ [that he spent the entire day doing something at the mall] but [(that) doing what we don't know] ] ] is disconcerting.

In $(20 \mathrm{a}-\mathrm{c})$, Ross's example, delimited by $[2 \ldots]$, is presented in various forms in a structural context that clearly involves embedding. Embedding within the subject DP is indicated by the brackets $[1 \ldots]$. Any potential matrix parse of the crucial string a picture of who (he has) we don't know is blocked by plural agreement, are, with the head of the subject DP reports. Bechhofer correctly predicts (20c) to be ungrammatical whether or not the question is elided. Similarly for VP pied-piping, for which only the crucial ungrammatical example is given, (20d).

We have thus established a contrast between clear root cases, (1a) and (16a), and clearly embedded cases, (20). Of course, roots are never selected, which suggests that a correct generalization across the cases considered so far is that the swamp construction is possible in unselected positions. Three contexts intended to distinguish roots from unselected embedded positions are tested below: clausal subjects, (21), extraposed clausal subjects, (22), and unselected embedded questions in the sense of Adger and Quer (2001), (23). None of these contexts allow the swamp construction, which seems to be restricted to roots and fronted under root coordination.

(21) a. *He has a picture of somebody, but a picture of who is surprising.

b. *He spent the entire day doing something at the mall, but doing what is surprising.

(22) a. *He has a picture of somebody, but it is surprising a picture of who.

b. *He spent the entire day doing something at the mall, but it is surprising doing what.

(23) a. *They have a picture of someone in the backroom, but the bartender didn't tell me a picture of who.

b. *He spent the entire day doing something at the mall, but the security guard wouldn't tell me doing what. 
Bechhofer's approach limits the swamp construction to true roots and root coordination. ${ }^{10}$ For Bechhofer, root coordination subsumes Ross's example (1a) via the analysis of the matrix as a parenthetical.

\subsection{Abe's (2015) in-situ analysis}

Abe (2015) analyzes the swamp construction against the background of his in-situ approach to sluicing. Within that analysis, and assuming the copy theory of movement, the pre-sluice for a canonical sluicing example like (24) is given in (24a).

He has a picture of somebody, but I don't know who.

a. $\ldots<$ who $>$ he has a picture of $<$ who $>$.

Unlike in Ross's analysis, this structure does not feed into ellipsis of a clausal constituent but instead into non-constituent ellipsis, (25). The ellipsis operation spares constituents marked with the [Focus]-feature. As shown in (25), both members of the wh-chain are unaffected by ellipsis but, Abe suggest, the lower member is actually pronounced in sluicing. This is indicated by the subscript [PF]. The low copy is pronounced because in chain links that do not cross overt material (or $w h$-traces) the low copy (if any) is pronounced:

$$
\text { ... but I don't know }<\text { who }>_{[\text {Focus] }} \text { he has a pieture of }<\text { who }>_{[\text {Focus] }}[\mathrm{PF}]
$$

In Ross's example, this normal course of events is disturbed by topicalization of a picture of who into the matrix. The moving constituents and their copies are again enclosed in acute brackets in the following structure and annotated with the movement inducing properties (topic and $w h$ ), the ellipsis-suspending [Focus] property, and the allocation of $[\mathrm{PF}]$ properties to the chain for clarity:

$$
\begin{aligned}
& \ldots \text { but }<\text { a picture of }<\text { who }>_{w h}>_{\text {topic }[\text { Focus }][\mathrm{PF}]} \text { I don't know }<\text { who }>_{w h} \text { he has } \\
& <\text { a picture of }<\text { who }>_{w h}>_{\text {topic[Focus }]}
\end{aligned}
$$

\footnotetext{
${ }^{10}$ Given that Bechhofer assimilates the swamp construction to the root process of fragment formation, we might expect the swamp construction to be possible in embedded root contexts to the same extent that embedded fragments are (see Temmerman 2013; Ott 2015; Griffiths 2015; Wurmbrand 2017 for discussion and references). A candidate verb allowing embedded fragments and embedded questions is confess, (ia-b). However, recall that Bechhofer crucially relies on a $w h$-in situ derivation for the swamp construction. English embedded questions never allow $w h$-in situ, (ic), so the conditions that might enable the swamp construction, (id) can never be met because simultaneous availability of fragment formation and $w h$-in situ is never given.
}

(i) a. Q: How many press-ups did you do at the gym today?

A: I confess, only three.

(Griffiths 2015:209, ex. (50b))

b. He confessed where he hid the loot.

c. He confessed he hid the loot where.

ok as direct echo/incredulity question

* as matrix declarative with indirect question $(=(\mathrm{ib}))$

d. *He stole a picture of somebody but never confessed a picture of who. 
As we have just seen, who would normally be pronounced in-situ under Abe's approach but, since this low copy is now part of a separate overt movement chain, it is pronounced within that chain.

The non-elliptical version of this derivation is the ungrammatical remnant movement structure in (27).

$$
\text { *... but a picture of I don't know who he has. }
$$

To rule out (27), Abe assumes that wh-movement of who and topicalization of a picture of (who) constitute the same type of movement. (27) is then a violation of Müller's generalization: Movement of type X does not feed remnant movement of the same type (Müller 1998; Takano 2000). ${ }^{11}$ To capture the distinction in acceptability between Ross's example and (27), Abe suggests treating Müller's generalization not in the narrow syntax but as a problem of linearization. ${ }^{12}$

There is a conceivable alternative pre-sluice for Ross's example, namely (1b). This structure features a fronted sluice rather than a fronted remnant:

$$
\begin{aligned}
& \ldots \text { but }<<\text { a picture of who }>\text { he has }<\text { a picture of who }>>\text { I don't know }<<\text { a } \\
& \text { picture of who }>\text { he has }<\text { a picture of who }>>
\end{aligned}
$$

Abe rules out (28) on the reasonable grounds that the $w h$-feature on the complementizer within the sluice would not be able to be checked properly, because the $w h$-word is buried too deeply within Spec,CP. This is what rules out massive pied-piping quite generally.

I suggested above that the elliptical version of (1e), repeated here as (29), has two derivations: one as a swamp structure and one as a fronted sluice. Abe by contrast suggests that example (29) is unambiguous and lacks a sluicing analysis. That is, Abe suggests that (29) necessarily involves topicalization of the remnant rather than topicalization of the sluice. ${ }^{13}$

He has a picture of somebody, but who I don't know.

For Abe, the pre-elliptical structure of (29) is only (30a) and cannot be (30b).

\footnotetext{
${ }^{11}$ The assumption that $w h$-movement and topicalization constitute the same type of movement for the purposes of Müller's generalization is empirically wrong and leads to undergeneration. It would have seemed more promising if Abe had subsumed the ungrammaticality of (27) instead under the generalization that categories containing unbound intermediate traces cannot undergo remnant movement. For discussion of both issues, relevant examples, and references see (Müller 1998:Chap. 1.3.4 and Chap. 6).

${ }^{12}$ The mechanism by which (27) comes out as a problem for linearization is the entirely ad hoc and complicating assumption that " $[\mathrm{t}] \mathrm{he}$ decision of which occurrence of a non-trivial chain carries its $[\mathrm{PF}]$ feature is made upon the completion of producing the chain involved, except for the case where a phrase carrying a feature $\mathrm{F}$ is properly contained in another phrase carrying $\mathrm{F}$. In that case, the decision is postponed until both Fs are satisfied" (Abe 2015:63,\#63). Not only is this ad hoc, it also flies in the face of the strictly derivational approach Abe endorses whereby "features [including the [PF] feature, K.A.] are not copied when Internal Merge (= Move) is applied but rather they are scattered" (Abe 2015:16).

${ }^{13} \mathrm{Abe}$ is forced into this position because of his assessment that the swamp construction and also examples like (29) show sensitivity to islands within the sluice (see Appendix B for discussion). It then follows from Abe's approach to island amelioration under sluicing that derivations like (26) and (30a) should show island sensitivity within the sluice but (30b) should not.
} 
a. ... but $<$ who $>_{\text {whtopic[Focus] }[\mathrm{PF}]}$ I don't know $<$ who $>_{\text {whtopic[Focus] }}$ he has at picture of $<$ who $>_{\text {whtopic }[\text { Focus] }}$

b. ... but $<<$ who $>_{w h[\text { Focus }]}$ he has a picture of $<$ who $>_{w h[\text { Focus }][\mathrm{PF}]}>_{\text {topic }[\mathrm{PF}]}$ I don't know $<<$ who $>_{w h[\text { Focus }]}$ he has a picture of $<$ who $>_{w h[\text { Focus }]}>_{\text {topic }}$

Abe does not address the question of how to rule out (30b) and it is not at all clear how he could. We need not pursue this particular issue further, though; the arguments given in this and the next section show that neither Ross's example nor (29) can involve topicalization of the remnant but must involve fronting of a CP.

We extract two claims from Abe's account for further scrutiny. First, according to Abe it is the remnant that is fronted rather than the indirect question and, therefore, the category of the fronted element should always be the category of the remnant (DP in Ross's example (1a)) and not that of the indirect question (CP). We will investigate this claim in Sect. 3. Second, the process giving rise to the swamp construction is topicalization. Topicalization is possible in root clauses and in coordinations of root clauses. Presumably, Abe intends this to explain the distribution of the swamp construction. We will now test whether or not the distribution of the swamp construction tracks the availability of topicalization.

The first potential problem arises, maybe surprisingly, for Ross's example (1a) and the root version of it (15a). Consider the following data first.

a. (i) ?Joe has a picture of Nixon, but a picture of Kennedy I don't know who has.

(ii) ??Joe buys the New York Times, but read it I don't know who does.

b. (i) *Joe has a picture of Nixon, but a picture of Kennedy, I don't know who.

(ii) *Joe buys the New York Times, but read it I don't know who.

The examples show that topicalization from a question is only mildly deviant, (31a), but topicalization from a sluice, (31b), is sharply ungrammatical. On the face of it this is very problematic for Abe's approach, since his derivations involve topicalization from a sluice. However, it should be pointed out that (31b) is probably independently ruled out by the condition that the wh-phrase in sluices must bear heavy stress (Hartman 2005). This condition is not met here.

Next consider the Abe-style pre-sluice for (15a), which is pronounced simply as A picture of who?:

$<$ a picture of $<$ who $>_{w h[\mathrm{PF}]}>_{\text {topic }[\mathrm{PF}][\text { Focus }]}\left[<\right.$ who $>_{w h}$ does he have $<$ a picture of $\left.\left.\langle\text { who }\rangle_{w h}\right\rangle_{\text {topic }[\text { Focus] }}\right]$

The remnant here is topicalized past the wh-phrase. This structure is problematic, because topicalization past a $w h$-phrase is not possible in root questions (see Bianchi and Frascarelli 2010:77, ex. (47), where the following example is taken from):

a. *These petunias, did John plant?

b. *These petunias, when did John plant? 
Further, the contrast between these examples and the only mildly deviant (31a-i) shows that we are not simply dealing with an island effect here that could be repaired by sluicing. Thus, it is unclear what the basis for Abe's claim is that topicalization of the remnant underlies the swamp construction and accounts for its distribution. Abe's account faces a fairly serious issue of undergeneration since neither of the two environments where the swamp construction occurs are environments where topicalization does.

An extension of this problem comes from the following data point, which simply attempts to embed (15a) under wonder.

A: He has a picture of somebody.

$\mathrm{B}$ : *I wonder a picture of who(m)?

B's response in (34) is unacceptable. To explain this fact, Abe would presumably invoke the idea that "topicalization does not occur in embedded interrogative clauses" (Abe 2015:56). This is true and the claim can easily be verified using the embedded versions (35) of Bianchi and Frascarelli's examples (33). But Abe cannot use this fact, because topicalization to the edge of direct questions is also impossible, as (33) above showed. A root-embedded asymmetry, required to get Abe's account off the ground, simply does not seem to be there. Other topic-like phrases to the left of the wh-phrase also fail to support the sharp root-embedded asymmetry: (36a) and (36b) are essentially well-formed.

a. *I wonder these petunias $\{$ if $\mid$ whether $\}$ John planted.

b. *I wonder these petunias when John planted.

a. When you get home, what do you want to do?

(McCloskey 2006:10, ex. (31a))

b. ?I wonder when we get home what we should do.

(McCloskey 2006:16, ex. (57b))

Setting these serious worries aside for now, we turn to the question of whether the distribution of the swamp construction tracks the distribution of topicalization in other cases. The following examples are telling. They involve the matrix predicates glad and tell. According to Bianchi and Frascarelli (2010), these predicates allow embedded topicalization, as shown in (37) (Bianchi and Frascarelli 2010:69, ex. (39)).

a. I am glad that this unrewarding job, she has finally decided to give up.

b. Mary didn't tell us that Bill she had fired, and John she had decided to promote.

Nevertheless, glad and tell fail to allow the swamp construction in their complement:

a. (i) *He has a picture of someone, but I sure am glad that a picture of who nobody knows.

(ii) *He spent the entire day doing something at the mall, but I sure am glad that doing what nobody knows. 
b. (i) *He has a picture of someone, but you never told us that a picture of who nobody knows.

(ii) *He spent the entire day doing something at the mall, but you never told us that doing what nobody knows.

The swamp construction then does not seem to share the distribution of topicalization.

As we have seen, Abe's claim that the swamp construction involves topicalization runs into distributional difficulties. In direct questions, swamp is possible but topicalization is impossible. In indirect questions, swamp is impossible and so is topicalization. In embedded declaratives where topicalization is possible, swamp is impossible.

The current account, which relates the swamp construction to left-dislocation, does not run into the same difficulties. Left dislocation is possible in direct questions ((39) from Bianchi and Frascarelli 2010:77, ex. 46), in root coordinated declaratives ((40) based on Bianchi and Frascarelli 2010:62, ex. 22), and impossible under glad and tell ((41) from Bianchi and Frascarelli 2010:76, ex. 45):

a. These petunias, did John plant them?

b. These petunias, when did John plant them?

A: What can you tell me about John?

B: I can't tell you anything about John, but Bill, Mary kissed him.

a. *I am glad that this unrewarding job, she has finally decided to give it up.

b. *Mary didn't tell us that Bill she had fired him.

Furthermore, Bianchi and Frascarelli (2010:75) note that most of their "English informants did not easily accept embedded L[eft] D[islocation] as such." Unlike Abe's account, which has difficulties in accounting for the distribution of the swamp construction, the current approach promises to get the distribution right. The issue will be taken up in more detail in Sect. 4.

\subsection{Summary}

In this section we have seen that swamp clauses can appear as root clauses and fronted in root coordination but apparently nowhere else. The German swamp construction and contrastive left-dislocation with clausal ellipsis show the same distribution (see Appendix A for data).

The distribution we find is in line with the expectations of Bechhofer's analysis. When it comes to distribution, Abe's analysis misgenerates rather dramatically. The open issues for the next section include the following questions: Is the relation between the swamp clause and its apparent matrix one of syntactic subordination (as per Abe's and the current analyses) or one of parenthesis (as suggested by Bechhofer)? Is the fronted constituent clausal (as per Bechhofer's and the current analyses) or is the category of the fronted constituent that of the remnant (as suggested by Abe)?

\section{Clausal subordination and clausal fronting}

In this section we will investigate the two questions mentioned immediately above. We will see that there is strong evidence that swamp clauses are subordinated and that 
the fronted constituent must be a clause and cannot be the remnant alone. German examples parallel to the ones discussed in the text for English are given in Appendix A, examples (112)-(116).

\subsection{Embedding or parenthesis}

In this subsection we will use two customary diagnostics to distinguish embedding from parenthesis: binding and word order. ${ }^{14}$

Typical cases of parenthesis are characterized by a lack of binding relations between the parenthetical expression and its host. This is illustrated in (42a) by the lack of condition $C$ effects in either direction. In embedding structures, (42b), we do find the effects of condition $\mathrm{C}$. Lack of binding effects is also shown by the impossibility of variable binding by a quantifier between host and parenthetical in either direction, (42c), while such binding is of course possible, subject to c-command and scope, in embedding structures, (42d).
a. (i) $\mathrm{John}_{\mathrm{j}}$ bought, he $\mathrm{j}_{\mathrm{j}}$ claims, all the necessary books.
(ii) $\mathrm{He}_{\mathrm{j}}$ bought, $\mathrm{John}_{\mathrm{j}}$ claims, all the necessary books.
b. (i) $* \mathrm{He}_{\mathrm{j}}$ claims (that) $\mathrm{John}_{\mathrm{j}}$ bought all the necessary books.
(ii) $\mathrm{John}_{\mathrm{j}}$ claims (that) he $\mathrm{j}_{\mathrm{j}}$ bought all the necessary books.
c. (i) $* \mathrm{He}_{\mathrm{n}}$ bought, nobody $\mathrm{y}_{\mathrm{n}}$ claims, all the necessary books already.
(ii) $*$ Nobody $_{\mathrm{n}}$ bought, he $\mathrm{n}_{\mathrm{n}}$ claims, all the necessary books already.
d. (i) Nobody $y_{n}$ claims (that) he $e_{n}$ bought all the necessary books already.
(ii) $* \mathrm{He}_{\mathrm{n}}$ claims (that) nobody $\mathrm{y}_{\mathrm{n}}$ bought all the necessary books already.

Second, the host in an appositive root structure shows root word order rather than embedded word order while true embedding shows the opposite pattern. This is illustrated through obligatory subject-auxiliary inversion in the host clause in (43a-b) and its impossibility (in standard English) in indirect questions.
a. What, Peter asks, can syntax do for him?
b. *What, Peter asks, syntax can do for him?
c. Nobody asks what syntax can do for him $_{n}$.
d. *Nobody $y_{\mathrm{n}}$ asks what can syntax do for him $\mathrm{n}_{\mathrm{n}}$.

[Standard English]

On both diagnostics swamp clauses pattern as embedded clauses rather than as hosts for parentheticals. Though vehicle change effects prevent testing condition $\mathrm{C}$ effects under ellipsis, variable binding into the swamp clause is clearly possible. Example (44) is a base line. It shows a regular sluicing construction with fronting of the question. The interpretation indicated in (44b), a plausible pre-sluice for (44a), with binding of they by nobody is clearly available. (45) is the swamp counterpart of the

\footnotetext{
${ }^{14}$ The discussion does not depend on any particular analysis of parenthesis and does not bear on the issue of whether the derivation of parentheticals involves embedding at some level of representation (see Schneider et al. 2015 for discussion and references).
} 
examples. The interpretation indicated in (45b) is available in (45a), although the actual examples in (45b) are, of course, unacceptable because of the illicit pied-piping.

a. Everybody will have to take a picture of somebody, but who, nobody knows yet.

b. Everybody will have to take a picture of somebody, but who they $\mathrm{y}_{\mathrm{n}}$ will have to take a picture of, nobody $\mathrm{y}_{\mathrm{n}}$ knows yet.

a. (i) Everybody will have to take a picture of somebody, but a picture of who, nobody knows yet.

(ii) Everybody will have to spend the entire day doing something at the mall, but doing what nobody knows yet.

b. (i) *Everybody will have to take a picture of somebody, but a picture of who they $\mathrm{w}_{\mathrm{n}}$ will have to take, nobody $\mathrm{y}_{\mathrm{n}}$ knows yet.

(ii) *Everybody will have to spend the entire day doing something at the mall, but doing what they $\mathrm{n}_{\mathrm{n}}$ will have to spend it at the mall nobody $_{\mathrm{n}}$ knows yet.

The interpretive facts thus suggest an embedding structure rather than a parenthetical structure.

Second, if swamp clauses were hosts in parenthetical structures, we'd expect corresponding full clauses (without massive pied-piping) to behave like hosts for parentheticals. The impossibility of subject-auxiliary inversion in (46) shows this not to be the case.

\footnotetext{
a. John has a picture of someone, but who he has a picture of, I don't know.

b. *John has a picture of someone, but who does he have he a picture of, I don't know. ${ }^{15}$
}

The word order facts thus also suggest embedding rather than parenthesis. It then seems safe to rule out Bechhofer's parenthetical analysis of the swamp construction on the basis of these rather clear diagnostics. The same is true for the German swamp construction and contrastive left-dislocation with clausal ellipsis, see (112)-(113) in Appendix A.

\subsection{The category of the fronted constituent}

In this subsection we address the question of whether the swamp construction involves fronting of the remnant alone (a DP in Ross's example (1a)) or of a clausal constituent. We will, in other words, evaluate the merits of the following two structures:

\footnotetext{
${ }^{15}$ This string of words is acceptable under an intonation that signals three independent clauses and with a clear break before I don't know: John has a picture of someone. || But who does he have a picture of? I| I don't know. This would serve as a representation of a quirky internal monologue, but this is neither the effect nor the intonation characteristic of the swamp construction.
} 
a.

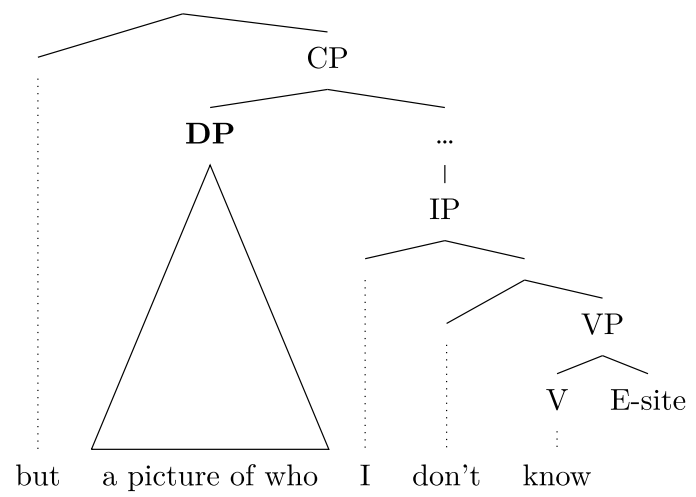

b.

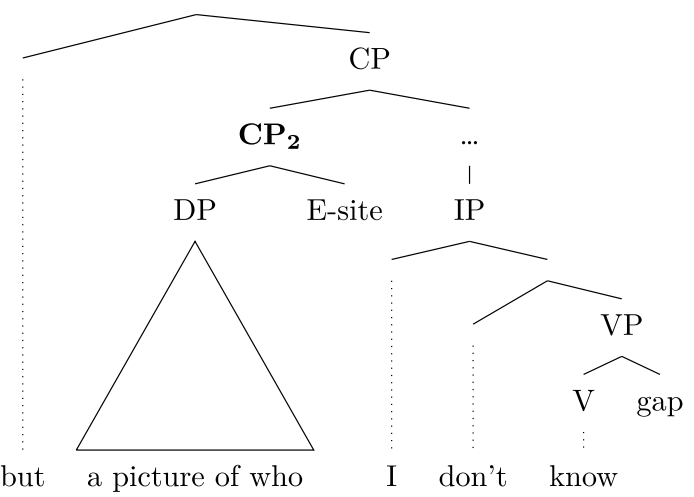

Structure (47a) is a representation of Abe's claim that what is fronted is only the remnant. Structure (47b) is an abstract representation of the claim made in the present paper, (14).

The first argument for (47b) and against (47a) depends on the observation that the availability of the swamp construction correlates with the availability of CP fronting. While not know in Ross's example readily allows CP fronting (see (44b) above), such fronting is impossible with other predicates. For example, extraposed subject wh-questions cannot readily be fronted, (48a) versus (48b). ${ }^{16}$

\footnotetext{
${ }^{16}$ I do not know why extraposing the $\mathrm{CP}$ is incompatible with fronting it. An anonymous reviewer suggests that (48b) might be ruled by competition with (i). Another option to consider might be that extraposition and fronting impose conflicting requirements on information structure. I leave the issue open since the argument here does not hinge on why extraposition and fronting cannot co-occur but hinges only on the fact that they do not do so.
} ... but what (causes the effect) is unclear.

Also, note the following attested counterexample (Available at https://twitter.com/RepAdamSchiff/status/ 846493210960637952. Accessed April 11, 2018): "Whether the documents support the argument that names were improperly unmasked or distributed, it is impossible to judge, but one thing is very clear: There was no legitimate justification for bringing that information to the White House instead of the committee." 
(48) a. Something causes this effect, but it is unclear what (causes this effect).

b. ??Something causes this effect, but [CP what (causes this effect)] it is unclear $\mathrm{t}_{\mathrm{CP}}$.

The same limitation shows up in the swamp construction. Example (49a) is minimally paired with (48a). (49a) violates the ban against massive pied-piping in regular embedded questions and regular sluicing. Example (49b) is minimally paired with (48b). The full version is ungrammatical for two reasons: (a) it violates the ban on fronting an extraposed question and (b) it violates the ban on massive pied-piping. The elliptical version of (49b) is a candidate for the swamp construction. Under the $\mathrm{CP}$ fronting hypothesis, (47b), we expect the elliptical version to remain ungrammatical: it violates the constraint against fronting an extraposed $\mathrm{CP}$ in exactly the same way that $(48 b)$ does.

a. *The influence of something causes this effect, but it is unclear [cP the influence of what (causes this effect)].

b. *The influence of something causes this effect, but the influence of what (causes this effect) it is unclear.

However, under the DP topicalization analysis, (47a), the structure of the elliptical version of (49b) would be as shown in (50a), which should be acceptable given that extraction from extraposed clauses causes no or only weak island effects, (50b) (see Szabolcsi 2006; Abrusán 2014 for discussion).

a. ... [DP the influence of what] it is unclear [eP tDP causes this effect]

b. Who was it scandalous that John invited $t_{\text {who }}$ to the party ${ }^{17}$ (Abrusán 2014:8, ex. (13a))

Another instructive set of contrasts can be constructed on the basis of data in Turnbull-Sailor (2007). Turnbull-Sailor (2007:13) discusses the contrast between wonder and discover in (51) and that between ask and determine in (52). The interesting observation is that wonder and ask can but discover and determine cannot follow their interrogative complements. ${ }^{18}$

(Turnbull-Sailor 2007:13, ex. (24))

a. They all wondered what could be done.

b. What could be done, they all wondered. ${ }^{19}$

c. They all discovered what could be done.

d. *What could be done, they all discovered.

\footnotetext{
${ }^{17}$ Attempts to extract from an extraposed $w h$-question show the expected $w h$-island effects, but to maintain the idea that the swamp construction involves fronting of the remnant alone, this effect needs to be nullified anyway (see Abe 2015:Chap. 4 for discussion).

${ }^{18}$ The claim here needs to be carefully hedged. For example, the prohibition against fronting does not inhere in discover and determine but has to do with whether the question has been resolved or not. Therefore, introducing negation in (51d) changes the judgment. The important point here is simply the very solid correlation in behavior.
} 
(Turnbull-Sailor 2007:13, ex. (25))

a. The juror asked who should be found guilty.

b. Who should be found guilty, the juror asked.

c. The juror determined who should be found guilty.

d. *Who should be found guilty, the juror determined.

DP topicalization in comparable cases gives rise to a $w h$-island effect with all four embedding predicates. When we turn to canonical sluicing, we find that regular sluicing shows the same pattern as full interrogative clauses: wonder and ask do but discover and determine do not allow fronting of the sluice:

a. He had eaten something poisonous. They all wondered what.

b. He had eaten something poisonous. What, they all wondered.

c. He had eaten something poisonous. They all discovered what.

d. *He had eaten something poisonous. What, they all discovered.

(54) The DA argued somebody's friend should be questioned.

a. ... The juror asked whose friend.

b. .... Whose friend, the juror asked.

c. ... The juror determined whose friend.

d. *... Whose friend, the juror determined.

This is unsurprising given that sluices are CPs. The same contrasts show up again in the swamp construction, as illustrated in (55). ${ }^{20}$

a. The DA argued a friend of somebody should be questioned.

(i) $\ldots$ A friend of who, the juror wondered.

(ii) *... A friend of who, the juror discovered.

b. The defendant had taken a picture of somebody.

(i) .... A picture of who, the prosecutor asked.

(ii) *... A picture of who, the prosecutor determined.

The pattern can easily be understood if the swamp construction obligatorily involves clausal fronting. Examples (51) and (52) are transparent cases of clausal fronting, as are examples (53) and (54) on the consensual assumption that sluices are clauses.

\footnotetext{
${ }^{19}$ The fronted question in examples like these show subject-auxiliary inversion but according to TurnbullSailor (2007:13-14) they still show behavior characteristic of embedded questions. The argument made here does not hinge on any particular resolution of this issue. See discussion below example (55).

${ }^{20}$ Similar judgments obtain for the structures based on Abe's example (6a):

(i) *He spent the entire day doing something at the mall but doing what it is unclear.

(ii) He spent the entire day doing something at the mall.

a. Doing what, the juror wondered.

b. *Doing what, the juror discovered.

The defendant spent the entire day doing something at the mall.

a. Doing what, the prosecutor asked.

b. *Doing what, the prosecutor determined.
} 
We can explain the pattern in (55) as a simple extension of the prohibition against fronting clauses under discover and determine if the swamp construction involves clausal fronting. The consistent patterning of clauses with remnants in the swamp construction remains mysterious. ${ }^{21}$ These paradigms thus suggest that both Ross's example and examples like (29) involve CP fronting obligatorily and cannot involve fronting of the remnant alone.

The second argument relies on the distribution of swiping to diagnose the structure of Ross's example. As mentioned above, swiping is the possibility, available only under sluicing, of inverting the preposition with its adjacent complement:

Joe was talking, but I can't remember what about.

Many analyses of swiping (see Ross 1969; Kim 1997; Richards 2001; Hasegawa 2006; Hartman 2007; Hartman and Ai 2009; van Craenenbroeck 2010; Larson 2014; Radford and Iwasaki 2015; Ott and Struckmeier 2018) attribute a structure to such examples in which the preposition and its complement do not form a constituent to the exclusion of the ellipsis site, $(57 \mathrm{a}-\mathrm{c})$. The alternative is an analysis with the structure in (57d), in which the preposition and its complement do form a surface constituent (van Riemsdijk 1978, Lobeck 1995, Chung et al. 1995, Merchant 2002).

$$
\begin{array}{ll}
\text { a. } & \ldots[\mathrm{CP} \text { what } \ldots[\text { about }[\ldots \text { E-site }]]] \\
\text { b. } & \ldots[\text { CP what } \ldots[[\ldots \text { E-site }] \text { about }]] \\
\text { c. } & \ldots[\text { CP what } \ldots[\text { E-site } \ldots \text { about } \ldots]] \\
\text { d. } & \ldots[\text { CP }[\text { what about } \ldots][\ldots \text { E-site }]]
\end{array}
$$

Under the analyses in $(57 \mathrm{a}-\mathrm{c})$, further movement of the $w h$-DP alone, if possible, will not affect the preposition. Under such analyses $w h$-DP and preposition move together only if the entire CP moves.

The analysis of the swamp construction in (47a) with a fronted remnant relies on independent movement of the $w h$-remnant. Coupled with any of the approaches to swiping in $(57 \mathrm{a}-\mathrm{c})$, we predict $(58 \mathrm{a})$ to have a licit derivation as a swamp construction with the structure (58c). No such derivation is available under a CP fronting analysis of the swamp construction, (58d). The CP fronting analysis does not allow what and about to be separated by I don't know.
a. John was talking, but what about I don't know.
b. *John was talking, but what I don't know about. ${ }^{22}$
c. ... [CP what ${ }_{D P} I$ don't know [CP $t_{\text {what }}\left[\right.$ [ about $\left.t_{\text {what }}\right]$ Hohn was talking tPP] ] ]
d. $\ldots\left[\mathrm{CP}_{1}\left[\mathrm{CP}_{2}\right.\right.$ what $\left[\left[\mathrm{PP}\right.\right.$ about $\left.\mathrm{t}_{\mathrm{what}}\right]\left[\right.$ John was talking $\left.\left.\left.\mathrm{t}_{\mathrm{PP}}\right]\right]\right][\mathrm{I}$ don't know $\mathrm{t}_{\mathrm{CP}_{2}}$ ]]

\footnotetext{
${ }^{21}$ This conclusion is unaffected by the considerations raised in $\mathrm{fn} .19$, because even if the fronted questions in Turnbull-Sailor's original examples are root questions, the acceptable examples (55a-i) and (55b-i) should, under Abe's assumptions, be ambiguous between a derivation with a fronted remnant and one with an initial root question. While the structure with the initial root question is ruled out for (55a-ii) and (55b-ii) by the same condition that rules out examples (51d) and (52d), this should leave unaffected the second derivation, the derivation where the elliptical clause remains after the embedding verb and only the remnant is fronted. This DP-fronting derivation, though, appears to be systematically unavailable.
} 
The fact that (58a) is grammatical and that (58b) is ungrammatical then shows that $\mathrm{CP}$ fronting is and independent DP fronting is not available.

The argument can be avoided if the correct structure for swiping involves the structure in $(57 \mathrm{~d}) .^{23}$

The next argument involves multiple sluicing. Like the argument from swiping, this argument revolves around the observation that multiple remnants are not separable and the assumption that they do not form a surface constituent to the exclusion of the ellipsis site.

Multiple sluices, (59a) can be fronted in the contexts where the swamp construction occurs, (59b). (59b) has a straightforward derivation with CP fronting. Importantly, the two wh-phrases cannot be separated, (59c-d).

a. Every student talked about a paper, but [I don't know [CP [DP which student] [ [PP about which paper] tDP talked tPP ]]].

b. Every student talked about a paper, but which student about which paper I don't know.

c. *Every student talked about a paper, but which student I don't know about which paper.

d. *The advisor of every student talked about some paper, but the advisor of which student I don't know about which paper.

Under a standard analysis of multiple sluicing sketched in (59a) and the schema in (60) (see Merchant 2001; Richards 2001; Lasnik 2014; Boone 2015; Abels and Dayal 2017 among others), the contrast in (59) is expected if and only if there is $\mathrm{CP}$ fronting and no fronting of the individual remnants. If the swamp construction involves fronting of the remnant alone, then $(59 c-d)$ do not fall into place directly. Ruling them out will require additional assumptions. The important property of the standard analysis of multiple sluicing that this argument rests on is the assumption that the remnants do not cluster, that is, that they do not form a surface constituent to the exclusion of the ellipsis site. ${ }^{24}$

${ }^{22}$ Examples like (i) from Hartman and Ai (2009) look similar, but seem to involve a parenthetical construal of 'do you think,' as (ii) shows.

(i) Will I get married, and if so, who do you think with?

(ii) A: Everyone voted today.

B: Who did they $\{$ say $\mid$ *admit $\}$ for?

$\mathrm{B}^{\prime}$ : Who didn't anybody $\{$ say $\mid$ admit $\}$ they voted for?

$\mathrm{B}^{\prime \prime}$ : *For who didn't anybody $\{$ say $\mid$ admit $\}$ ?

$\mathrm{B}^{\prime \prime \prime}$ : *Who didn't anybody $\{$ say $\mid$ admit $\}$ for?

$\mathrm{B}^{\prime \prime}$ with 'say' casts doubt on the availability of long-distance clausal ellipsis. B"' with 'say' —on that of long distance swiping.

${ }^{23}$ Abe's (2015:18-20) analysis of swiping, while not exactly assuming the structure in (57d), does assume that $w h$-DP and preposition form a surface constituent. While Abe thus avoids the argument presented in the text, Appendix B shows that Abe's analysis of swiping massively overgenerates (see (121)) and I set his approach to swiping aside for this reason.

${ }^{24}$ Abe (2015) proposes that $w h$-phrases in multiple sluicing form a cluster. This proposal, of course, avoids the problem with the separated wh-phrases in (59). However, it is not clear to me what would force clus- 
(60)

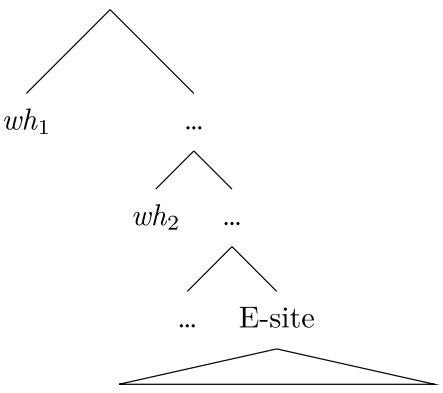

The previous two arguments were not directly about the swamp construction with its characteristic massive pied-piping. This was necessitated by the fact that neither swiping nor multiple sluicing seem compatible with massive pied-piping. The two previous arguments therefore only address the claim that all examples of the general shape of Ross's example must (or may) involve fronting of the remnant. The arguments suggest that this position (adopted in Abe 2015) is wrong and that, at the very least when massive pied-piping is absent, CP fronting is the only possibility. A further limitation of these last two arguments is that they stand and fall with specific assumptions about the surface constituency of swiping and multiple sluicing, namely that the $w h$-word and the preposition do not form a constituent to the exclusion of the question nucleus for swiping and that the $w h$-phrases do not cluster for multiple sluicing. The argument that follows draws on German data but is otherwise much more direct.

As noted above, German shows similar restrictions on pied-piping in embedded wh-questions as English (even if the parallel is not as tight as Webelhuth 1992; Heck 2008 claim). This is illustrated in (61a) and (61b) for the two types of pied-piping in (1a) and in (6a).

\section{German}

a. *Ich frage mich, die Gerüchte über wen ihn schockiert haben. I ask myself the rumors about who him shocked have (Webelhuth 1992:120, ex. (29) $)^{25}$

b. *Ich frage mich, um was zu erreichen er im Einkaufszentrum I ask myself in.order what to achieve he in.the mall war. was

tering of multiple wh-phrases under Abe's in-situ approach to sluicing because nothing in the theory as presented rules out assigning the [Focus] property, which, recall, allows a phrase to survive ellipsis, to more than one phrase. Of course, a stipulation can be added to the theory to the effect that only a single constituent within an ellipsis site can survive to PF. Apart from being unmotivated, this stipulation would not solve the problem posed by (59), because in the cases where the $w h$-phrases are separated, the ellipsis site contains only a single pronounced phrase on the surface.

${ }^{25}$ I noted above in connection with (10) that the German of many speakers appears to allow massive piedpiping more readily than English. Webelhuth's example given here does seem worse to me than pied-piping in (10) above. The choice of the definite determiner might play a role here. 
The constraints on pied-piping are also operative under regular sluicing. This was illustrated above in (10b) and (11b). Furthermore, Ross's and Abe's examples ((1a) and (6a)) can be translated into German, (10a) and (11a). These German translations show all the hallmarks of the swamp construction, that is, they show the characteristic three-way interaction between pied-piping, fronting, and ellipsis. In the German examples in question, the use of a contrastive left-dislocation structure is obligatory or at least strongly preferred: ${ }^{26}$ This is shown by the (near) obligatory presence of the d-pronoun, (62).

\section{German}

a. Die Gerüchte über jemanden haben ihn schockiert, aber die the rumors about someone have him shocked, but the Gerüchte über wen, *(das) weiss ich nicht. rumors about who dPR know I not 'The rumors about someone shocked him, but the rumors about who, I don't know.'

b. Hans hat ein Bild von jemandem, aber eine Bild von wem, Hans has a picture of somebody, but a picture of who ??(das) weiss ich nicht. ${ }^{27}$

\section{dPR know I not}

'Hans has a picture of somebody, but a picture of who I don't know.'

c. Er war den ganzen Tag im Einkaufszentrum, um dort he was the whole day at.the mall in.order there etwas zu erledigen, aber um dort was zu erledigen, *(das) something to deal.with but in.order there what to deal.with dPR weiss ich nicht.

I know not

'He was the whole day at the mall to take care of something, but to take care of what I don't know.'

For the present argument, it is important to recall from above that contrastive leftdislocation involves a d-pronoun resuming the left dislocate. The d-pronoun agrees in number, gender, and case with the left dislocated phrase and both the d-pronoun and the left dislocate show case connectivity into the clause internal position. These properties are illustrated in the following examples. (63d) also shows that the d-pronoun is not necessarily homophonous with the corresponding definite article. (Note that obligatory case connectivity between left dislocate and resumptive element is absent in hanging-topic left-dislocation, as discussed in connection with example (77) below.)

\footnotetext{
${ }^{26}$ Spanish (L. Martí, p.c.) appears to require clitic left-dislocation in translations of Ross's example and in Swedish (B. Lundqvist, p.c.), like German, contrastive left-dislocation. I have not had a chance to investigate these languages more deeply.

${ }^{27}$ As noted, massive pied-piping of indefinite DPs is more acceptable than massive pied-piping of definite DPs both in full questions and in sluices. This is probably the source of improvement in this example.
} 
(63) German
a. $\{$ Den
|*Dem $\}$
Mann, \{den
the.M.SG.ACC the.M.SG.DAT man dPR.M.SG.ACC
*dem $\}$ habe ich gesehen.
dPR.M.SG.DAT have I seen
'The man, I saw him.'
b. $\{*$ Den
| Dem
Mann, $\{*$ den
the.M.SG.ACC the.M.SG.DAT man
dPR.M.SG.ACC
dem $\}$ habe ich geholfen.
dPR.M.SG.DAT have I helped
'The man, I helped him.'
c. $\{*$ Den $\quad$ Mann, $\mid$ Die $\quad$ Frau, $\}$ die habe
the.M.SG.ACC man the.F.SG.ACC woman dPR.F.SG.ACC have ich gesehen.
I seen
'The woman, I saw her.'
d. Den Männern, $\left\{{ }^{*}\right.$ dem $\quad$ denen $\}$ habe ich
the.PL.DAT men dPR.M.SG.DAT dPR.PL.DAT have I
geholfen.
helped
'The men, I helped them.'

Clauses are resumed by the third person singular neuter form of the d-pronoun or, when they originate inside of a PP, with the r-pronoun $d a$ or the appropriate prepositional adverb. DPs are not resumed by r-pronouns or prepositional adverbs.

(64) German

a. $\quad$ Wen er eingeladen hat $\mid$ Dass er Hans eingeladen hat

who he invited has that he Hans invited has

\{das $\mid *$ den $\quad \mid *$ die $\quad *$ da

dPR.N.SG.ACC dPR.M.SG.ACC dPR.F.SG.ACC/PL.ACC there

soll niemand erfahren.

shall nobody find.out

' $\{$ Who he invited | That he invited Hans $\}$, nobody is supposed to find out.'

b. $\quad$ Wen er eingeladen hat $\mid$ Dass er Hans eingeladen hat $\}$ da who he invited has that he Hans invited has there

*das $\quad$ redet niemand drüber. dPR.N.SG.ACC talks nobody there.about

' $\{$ Who he invited | That he invited Hans $\}$, nobody talks about.'

c. $\quad\{$ Wen er eingeladen hat $\mid$ Dass er Hans eingeladen hat $\}$ darüber | who he invited has that he Hans invited has there.about *da $\mid *$ das $\} \quad$ redet niemand.

that dPR.N.SG.ACC talks nobody

' $\{$ Who he invited | That he invited Hans $\}$, nobody talks about.' 
Purpose clauses are resumed by a prepositional adverb as well:

\section{German}

Peter war im Einkaufszentrum, um dort etwas zu erledigen, Peter was at.the mall in.order there something to deal.with aber um dort einen Vogel zu kaufen, \{darum |deshalb but in.order there a bird to buy there.about that.cause |*das $\quad$ war er sicher nicht dort. dPR.N.SG.ACC was he certainly not there

'Peter was at the mall to do something there, but he certainly wasn't there to buy a bird.'

The fact that the resumptive element agrees in $\phi$-features with nominal left dislocates but is invariably third singular neuter, an r-pronoun, or a prepositional adverb with a clausal left dislocate allows us to test the category of the fronted constituent in the German renditions of the swamp construction. The examples below show clearly that the fronted constituent must be a clause. The resumptive element in all of the below examples invariably has to be the third singular neuter d-pronoun independently of the gender of the head noun of the remnant, (66), the case of the remnant, (67), or the number of the remnant, (68).

(66) German

a. Er hat das Bild von jemandem mitgenommen, aber das he has the picture $(\mathrm{N})$ of somebody with.taken, but the Bild von wem $\{$ das $\quad *$ den picture $(\mathrm{N})$ of who dPR.N.SG.ACC dPR.M.SG.ACC *die \} weiss ich nicht. dPR.F.SG.ACC know I not 'He took the picture of somebody, but the picture of who I don't know.'

b. Er hat die Zeichnung von jemandem mitgenommen, aber die he has the drawing(F) of somebody with.taken, but the Zeichnung von wem $\{$ das $\quad *$ den drawing(F) of who dPR.N.SG.ACC dPR.M.SG.ACC *die \} weiss ich nicht. dPR.F.SG.ACC know I not

'He took the drawing of somebody, but the drawing of who I don't know.'

c. Er hat den Steckbrief von jemandem mitgenommen, aber den he has the wanted.poster(M) of somebody with.taken, but the Steckbrief von wem $\{$ das $\quad$ *den wanted.poster(M) of who dPR.N.SG.ACC dPR.M.SG.ACC *die \} weiss ich nicht. dPR.F.SG.ACC know I not

'He took the wanted poster of somebody, but the wanted poster of who I don't know.' 

German
Er hat dem Bruder von jemandem geholfen, aber
he has the.M.SG.DAT brother(M) of somebody helped but
dem Bruder von wem, $\{$ das
the.M.SG.DAT brother of who dPR.N.SG.ACC
*dem\} weiss ich nicht.
dPR.M.SG.DAT/N.SG.DAT know I not
'He helped the brother of someone, but the brother of who I don't know.'
Er hat die Bilder von jemandem mitgenommen, aber die Bilder von he has the pictures of somebody with.taken but the pictures of wem $\{$ das $\quad$ *die $\} \quad$ weiss ich nicht.
who dPR.M.SG.ACC dPR.PL.ACC know I not
'He has pictures of somebody, but pictures of who I don't know.'

(68) German

The possibility of the neuter singular resumptive in all of these examples shows that the category of the fronted constituent may be $\mathrm{CP}$ and the impossibility of $\phi$ agreement with the head of the remnant shows that fronting of the DP alone is strictly impossible. An Abe-style DP fronting derivation for (66b) is schematized in terms of English glosses below. It shows why Abe's analysis gives rise to the wrong expectations regarding the resumptive: 28

\section{... but [DP the drawing(F) of who] dPR.F.SG.ACC know I not fep [of whe] \\ [he [dPR.F.SG.ACC [the drawing of who] with.taken has ]]]}

The conclusion that the resumptive element obligatorily resumes the silent clausal complement of wissen-'to know' can equally be based on the German translation of Abe's example, (11a) above. It is significant that in (11a) the resumptive pronoun surfaced as das rather than darum or deshalb. Replacing das by darum or deshalb leads to sharp ungrammaticality. This shows that the overtly registered left dislocate in (11a) is the silent complement of wissen rather than the overt purpose clause.

The conclusion that the left dislocate is a clause is further corroborated when we consider clauses that act as the complements of a preposition. The resumptive element is either the r-pronoun or the appropriate prepositional adverb, (70). The $\phi$-agreement expected under an account where the remnant alone is left dislocated, (69) above, would lead to sharply ungrammatical examples like (71).

German

a. Er hat das Bild von jemandem mitgenommen, aber das Bild von he has the picture of somebody with.taken but the picture of wem, $\{$ da $\mid *$ das $\} \quad$ redet er nicht drüber.

who there dPR.N.SG.ACC talks he not there.about 'He took the picture of somebody, but the picture of who he doesn't talk about.'

\footnotetext{
${ }^{28}$ For concreteness and simplicity I assume an analysis of contrastive left-dislocation in the schematic structure according to which left dislocate and resumptive form an underlying constituent. As far as I can tell, nothing in the argument hinges on this assumption. Any analysis of contrastive left-dislocation gives rise to the same prediction concerning the form of the resumptive.
} 
b. Er hat das Bild von jemandem mitgenommen, aber das Bild von he has the picture of somebody with.taken but the picture of wem, $\{$ darüber $\mid *$ das $\} \quad$ redet er nicht.

who there.about dPR.N.SG.ACC talks he not

'He took the picture of somebody, but the picture of who he doesn't talk about.'

\section{(71) German}

*Er hat die Zeichnung von jemandem mitgenommen, aber die Zeichnung he has the drawing(F) of somebody with.taken but the drawing(F) von wem, die redet er nicht darüber. of who dPR.F.SG.ACC talks he not there.about

The pattern of judgments clearly indicates that the fronted constituent may and must be a $\mathrm{CP}$ and cannot be a DP.

We can use word order instead of the features of the d-pronoun to reach the same conclusion. Altmann (1981:Sect. 10.2) notes that clausal arguments of prepositions cannot be topicalized in German but must be left dislocated. The characteristic property of left-dislocation is the V3 order. Altmann's observation is illustrated in (72). The point to note is that in this class of cases, the finite verb in the main clause cannot directly follow the fronted clause.

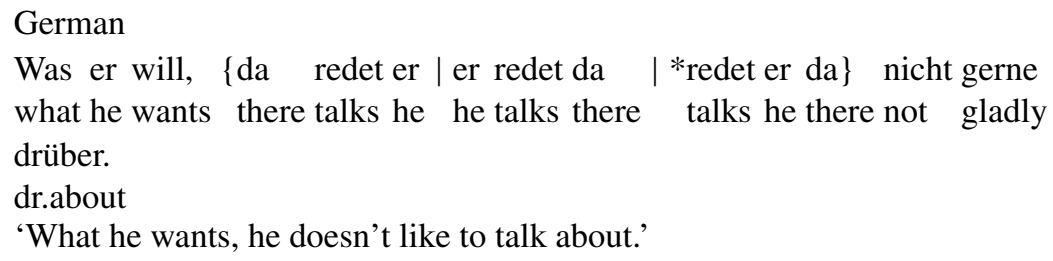

Observe now that the fronted constituent in the swamp construction behaves like a clause and not like any other kind of constituent in that the finite verb cannot immediately follow it:

\section{German}

Er hat die Zeichnung von jemandem mitgenommen, aber die Zeichnung he has the drawing(F) of somebody with.taken but the drawing(F) von wem, $\{$ da redet er $\mid$ er redet da $\mid$ *redet er da $\}$ nicht drüber. of who there talks he he talks there talks he there not dr.about

Again we see that, as in English, the swamp construction involves fronting of a $\mathrm{CP}$ rather than of a DP.

This subsection has provided evidence which bears on the question of whether the fronted constituent in Ross's example (1a) is the remnant alone (a DP) or whether it is a clausal constituent (a CP). The position according to which only the remnant is fronted is not supported by the facts. The facts point strongly to a structure with a fronted (elliptical) clause. 
In this section we have tried to answer the questions raised by Bechhofer's and Abe's analyses of the swamp construction. Bechhofer's analysis, according to which the apparent sluice is a root and the apparent matrix is a parenthetical, cannot be maintained; binding and word order suggest true embedding. We also found that Abe's claim that in Ross's example (1a) only the remnant, a DP, is fronted, while the CP is left in its canonical position, cannot be maintained either (with German patterning again like English); the swamp construction involves a fronted clause, a CP, rather than merely a fronted remnant. Section 2 had already shown that Abe's approach overgenerates (and possibly also undergenerates) when it comes to the distribution of the swamp construction. Bechhofer's analysis, as far as can be determined, describes the distribution correctly. Putting together the results from both sections, we find that neither of the existing accounts satisfactorily deals with the properties of the swamp construction.

\section{Swamp = Contrastive Left Dislocation with Question Ellipsis}

The previous sections have shown that neither of the existing accounts of the swamp construction is descriptively adequate. They have also established a number of facts that any successful analysis is responsible for. We have seen that the swamp construction involves subordination of the elliptical question, that the fronted constituent is an elliptical clause, and that the overall structure has a distribution limited to root contexts and coordinations of roots.

The proposed analysis for Ross's example (1a) is repeated below, (74). The analysis says that the remnant is left-dislocated from its containing question. The question then elides. The analysis entails that the swamp construction relies on the simultaneous availability of contrastive left-dislocation from a question and ellipsis of that question.

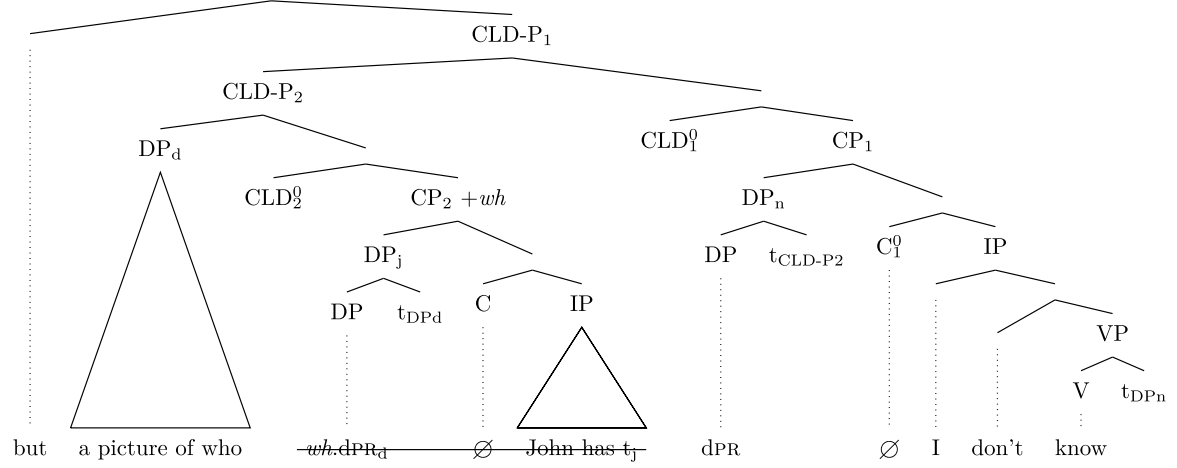

We have already seen that contrastive left-dislocation from a question with ellipsis of that question are available under root coordination, (13b) above. Evidence pertaining to root questions comes from the following imagined dialogue between two detectives: 

A: Wir wissen, wer das
Mädchen zuletzt gesehen hat. we know who the.ACC.N.SG girl last seen has 'We know who last saw the girl.'
a. B: Und den Jungen?
and the.ACC.M.SG boy?
'And the boy?'
b. B: Und den Jungen, wer hat den zuletzt
and the.ACC.M.SG boy who has dPR.ACC.M.SG last
gesehen?
seen
'And the boy, who has seen him last?'

B's response in (75a) is entirely natural and can easily be interpreted as in (75b). ${ }^{29}$ This suggests a derivation in terms of contrastive left-dislocation followed by ellipsis of the question. Ellipsis of the question is parallel to what we saw in (13b). Examples (13b) and (75) thus provide prima facie evidence for the availability of both contrastive left-dislocation and question ellipsis in root environments and in the type of syntactic frame we find in Ross's example (1a): fronting under root coordination.

The structure of the rest of this section is as follows. I review case and binding connectivity in contrastive left-dislocation and explicitly compare contrastive leftdislocation with hanging-topic left-dislocation. I then show that examples (13b) and (75a) behave like contrastive left-dislocation and in agreement with the properties of the swamp construction established in the previous section. Finally it will be shown that contrastive left-dislocation with question ellipsis is not available in those contexts where the swamp construction is impossible.

Contrastive left-dislocation in German (Frey's 2004 German Left Dislocation) is well known for its connectivity effects (see Grewendorf 2009; Ott 2014, 2015). Indeed, Frey (2004) takes obligatory case connectivity between dislocate and resumptive and binding connectivity to be the crucial diagnostics distinguishing hangingtopic left-dislocation and contrastive left-dislocation. ${ }^{30}$ Contrastive left-dislocation, (76a), but not hanging-topic left-dislocation, (76b) shows obligatory case matching between the left dislocate and the resumptive element.

\footnotetext{
${ }^{29}$ The interpretation in (75b) is most natural when the first person plural pronoun in A's utterance is read inclusively. When it is given an exclusive reading, the interpretation of B's utterance shifts to something like (i). I'm indebted to J. Merchant (p.c.) for pointing out this alternative interpretation.
}

\begin{tabular}{|c|c|c|}
\hline a. & $\mathrm{B}^{\prime}:$ & Und den Jungen, wisst ihr, wer den zuletzt gesehen hat? \\
\hline & & $\begin{array}{l}\text { and the boy know you who dPR.ACC.M.SG last seen has } \\
\text { 'And do you know who last saw the boy?' }\end{array}$ \\
\hline b. & $\mathrm{B}^{\prime}$ : & $\begin{array}{l}\text { Und den Jungen, wer hat den euch zufolge zuletzt gesehen? } \\
\text { and the boy who has dPR.ACC.M.SG you according.to last seen } \\
\text { 'And who last saw the boy according to you?' }\end{array}$ \\
\hline
\end{tabular}

Which of these two paraphrases is more appropriate bears on the issue of the island (in-)sensitivity of contrastive left-dislocation. I will not explore the issue further here.

${ }^{30}$ This approach, which I adopt, breaks with the older tradition which sees a resumptive d-pronoun in the left periphery of the clause and immediately following the left dislocate as the crucial diagnostic. Under Frey's (and Grewendorf's, and Ott's) approach (13a) and (13b) are instances of contrastive left-dislocation while under the older approach they are (by definition) not. 
 the.M.SG.ACC the.M.SG.NOM man(M) dPR.M.SG.ACC know I nicht.
a. $\{$ Den $\quad *$ Der $\} \quad$ Mann, den kenne ich
not
'The man, I don't know him.'

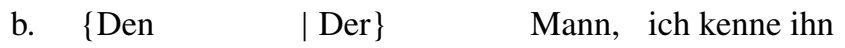
the.M.SG.ACC the.M.SG.NOM man(M) I know him.M.SG.ACC nicht.
not
'The man, I don't know him.'

Furthermore, a quantifier in clause internal position can bind a variable in the left dislocate under contrastive left-dislocation, (77a), but not under hanging-topic leftdislocation, (77b).
a. Seinen $_{1}$ Doktorvater, $\rightarrow$ den
verehrt jeder Linguist $_{1} .{ }^{31}$
his supervisor dPR.M.SG.ACC admires every linguist
'Every linguist admires his supervisor.'

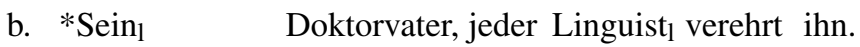 his.M.SG.NOM supervisor every linguist admires him

These core properties also characterize contrastive left-dislocation in questions. The possibility of contrastive left-dislocation in questions is illustrated in (78). ${ }^{32}$

a. Seinem 1 Doktorvater, würde *(dem) wenigstens ein his.M.SG.DAT supervisor would dPR.M.SG.DAT at.least one Linguist $_{1}$ Geld ausleihen $?^{33}$

linguist money lend

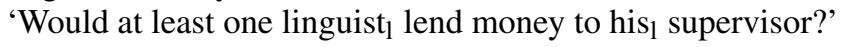

(Frey 2004:ex. (17b))

b. Den Käse, wann hat die Maus *(den)

the.M.SG.ACC cheese(M) when has the mouse dPR.M.SG.ACC gefressen?

eaten

'The cheese, when did the mouse eat it?'

CLD version from Haider (2010:3, ex. (5d))

Example (79) illustrates the possibility of variable binding into the left dislocate by a clause internal operator under contrastive left-dislocation. Example (80) shows that this is impossible under hanging-topic left-dislocation. The construal of the left dis-

\footnotetext{
${ }^{31}$ The arrow between left dislocate and resumptive pronoun is used in the literature to indicate the progredient intonation typical of contrastive left-dislocation.

${ }^{32}(78 \mathrm{~b})$ also shows that topicalization to the edge of a question is impossible in German (as in English, see (33) above).

${ }^{33}$ Without the resumptive d-pronoun, the example is, of course, acceptable as a declarative with topicalization and as a rising declarative- but not as a polar question.
} 
locate as a hanging topic is forced in (80) by the lack of case matching between left dislocate and resumptive.

a. Seinen ${ }_{n}$ besten Freund, warum sollte den niemand $_{n}$ his.M.SG.ACC best friend why should dPR.M.SG.ACC nobody betrunken autofahren lassen?

drunk car.drive let

'Why should nobody let his best friend drive while under the influence?'

b. Seinen Westen Freund, wer $_{\mathrm{w}}$ hat den betrunken

his.M.SG.ACC best friend who has dPR.M.SG.ACC nobody

autofahren lassen?

drunk car.drive let

'Who let his best friend drive while under the influence?'

a. ${ }^{*} \operatorname{Sein}_{\mathrm{n}} \quad$ bester Freund, warum sollte den niemand $_{\mathrm{n}}$ his.M.SG.NOM best friend why should dPR.M.SG.ACC nobody betrunken autofahren lassen?

drunk car.drive let

'Why should nobody let his best friend drive while under the influence?'

b. ${ }^{*} \operatorname{Sein}_{\mathrm{w}} \quad$ bester Freund, wer $_{\mathrm{w}}$ hat den betrunken

his.M.SG.NOM best friend who has dPR.M.SG.ACC nobody

autofahren lassen?

drunk car.drive let

'Who let his best friend drive while under the influence?'

Contrastive left-dislocation is also possible in questions that have been contrastively left dislocated under root coordination, that is, in syntactic frames that match Ross's example (1a) very closely. In the same context, hanging-topic left-dislocation is at best marginally possible. This is shown in the full versions of (81a) and (81b). As expected, contrastive left-dislocation does but hanging-topic left-dislocation does not allow binding of a variable in the left dislocate. The full versions of (82a) and (82b) illustrate this. The elliptical versions of the examples show furthermore that contrastive left-dislocation does but hanging-topic left-dislocation does not feed ellipsis of the question.

a. Ich weiß, wer das Handy vergessen hat, aber

I know who the.N.SG.ACC cellphone(N) forgotten has but

den Mantel, (wer den vergessen hat),

the.M.SG.ACC coat(M) who dPR.M.SG.ACC forgotten has

das weiß ich nicht.

dPR.N.SG.ACC know I not

'I know who forgot the cellphone, but I don't know who forgot the coat.' 
b. Ich weiß, wer das Handy vergessen hat, aber I know who the.N.SG.ACC cellphone(N) forgotten has but der Mantel, *(??wer den vergessen hat), the.M.SG.ACC coat(M) who dPR.M.SG.ACC forgotten has das weiß ich nicht. ${ }^{34}$ dPR.N.SG.ACC know I not 'I know who forgot the cellphone, but I don't know who forgot the coat.'

a. Ich weiß, wer $_{\mathrm{w}}$ seinem $_{\mathrm{w}}$ Hund teures Futter kauft, aber I know who his.M.DAT.SG $\operatorname{dog}(\mathrm{M})$ expensive food buys but seiner $_{\mathrm{x}}$ Katze, $\left(\right.$ wer $_{\mathrm{x}}$ der teures Futter kauft), das his.F.SG.DAT cat(F) who dPR.F.SG.DAT expensive food buys dPR weiß ich nicht.

know I not

'I know who buys expensive food for his dog, but I don't know who buys expensive food for his cat.'

b. *Ich weiß, wer $_{\mathrm{w}}$ seinem $_{\mathrm{w}} \quad$ Hund teures Futter kauft, aber I know who his.M.DAT.SG $\operatorname{dog}(\mathrm{M})$ expensive food buys but seine $_{\mathrm{X}}$ Katze, $\left(\right.$ wer $_{\mathrm{x}}$ der teures Futter kauft), his.F.SG.NOM cat(F) who dPR.F.SG.DAT expensive food buys das weiß ich nicht. dPR know I not

The analysis of Ross's example (1a) then predicts that core properties of the swamp construction and of contrastive left-dislocation should match. Indeed, we have seen that left dislocate and d-pronoun must match in case and this fact is mirrored by obligatory case matching between correlate and remnant in the swamp construction, (83a). Furthermore, we have seen that binding into the dislocate is possible and the same is true for remnants in the swamp construction, $(83 b){ }^{35}$

a. Er hat den Steckbrief von jemandem mitgenommen, he has the.M.SG.ACC wanted.poster(M) of somebody with.taken, aber $\{*$ der $\quad \mid$ den $\} \quad$ Steckbrief von wem, but the.M.SG.NOM the.M.SG.ACC wanted.poster(M) of who das weiß ich nicht.

dPR.N.SG.ACC know I not

'He took the wanted poster of somebody, but the wanted poster of who, I don't know.'

\footnotetext{
${ }^{34} \mathrm{D}$. Ott. (p.c.) judges both versions of this sentence as completely unacceptable while for me there is a contrast between the marginal full version and the completely unacceptable elliptical version. The important point here is that either way hanging-topic left-dislocation never feeds ellipsis of the question.

${ }^{35}$ For speakers of the liberal pied-piping variety of German, examples like (112b) in Appendix A are necessary to establish the point.
} 
b. Jeder Politiker ${ }_{p}$ hat seinen p $_{p} \quad$ Besuch in einer Stadt abgesagt, every politician has his.M.SG.ACC visit(M) in one city canceled aber seinen $_{\mathrm{p}} \quad$ Besuch in welcher Stadt, das weiß ich but his.M.SG.ACC visit(M) in which city dPR.N.SG.ACC know I nicht.

not

'Every politician canceled his visit to some city, but his visit to which city, I don't know.'

The reconstructive properties of contrastive left-dislocation also explain the embedding behavior of the swamp construction, illustrated in (45a) above and repeated here as (84).

(84) Everybody will have to take a picture of somebody, but a picture of who, nobody knows yet.

This behavior follows directly from the proposed analysis, because pronouns in left dislocated declarative and interrogative clauses can be bound by an operator in the matrix:

a. Dass er ${ }_{n}$ todkrank ist, das hat niemand $d_{n}$ verraten. that he mortally.ill is dPR.N.SG.ACC has nobody divulged 'Nobody ${ }_{n}$ divulged that they ${ }_{n}$ are mortally ill.'

b. Warum er $\mathrm{n}_{\mathrm{n}}$ so ein Gesicht macht, das hat niemand why he such a face makes dPR.N.SG.ACC has nobody verraten.

divulged

'Nobody divulged why they $_{n}$ are making such a face.'

The same effect also shows up under recursive left-dislocation with and without clausal ellipsis, (86). We have a further match here between the properties of the swamp construction and (recursive) contrastive left-dislocation (with clausal ellipsis).

(86) Jede Krankenschwester ${ }_{k}$ wusste, in welchen Mülleimer sie $_{k}$ die every nurse knew in which bin she the gebrauchten Handschuhe werfen sollte, aber die gebrauchten Nadeln, (in used gloves throw should but the used needles in welchen Mülleimer sie die werfen sollte,) das wusste which bin she dPR.PL.ACC throw should dPR.N.SG.ACC know keine.

none.

'Every nurse $\mathrm{k}_{\mathrm{k}}$ knew in which bin she $\mathrm{k}_{\mathrm{k}}$ had to throw the used gloves, but no nurse 1 knew in which bin she $e_{1}$ had to throw the used needles.'

Notice incidentally that the word order of left dislocated questions is that of an embedded question, matching our finding for English from Sect. 2.1. 
In Sect. 2 we showed that the swamp construction is impossible in selected complement questions, in extraposed questions, in subject questions, in unselected embedded questions, and under embedded coordination. We will now show that contrastive left dislocation with question ellipsis is impossible in all of these environments.

Contrastive left-dislocation is often characterized as a root phenomenon in German. Indirect questions resist embedded root phenomena such as embedded V2, (87).

a. Niemand $_{n}$ \{weiss | fragt sich | erinnert sich | hat darüber nobody knows asks self remembers self has there.about nachgedacht $\}$, wann er $_{n}$ den Jungen zuletzt gesehen hat. after.thought when he the boy last seen has 'Nobody ${ }_{n}\{$ knows|wonders|remembers|has thought about $\}$ when he last saw the boy.'

b. *Niemand $_{\mathrm{n}}$ [weiss | fragt sich | erinnert sich | hat darüber nobody knows asks self remembers self has there.about nachgedacht , wann hat $\mathrm{er}_{\mathrm{n}}$ den Jungen zuletzt gesehen. after.thought when has he the boy last seen *'Nobody ${ }_{n}\{$ knows|wonders|remembers|has thought about $\}$ when did he ${ }_{\mathrm{n}}$ last see the boy.'

Given this, it might be somewhat surprising that there are speakers for whom contrastive left-dislocation is not categorically incompatible with embedded questions. Thus, while for me (88) is certainly marked and maybe somewhat degraded, it is not sharply ungrammatical. Other speakers (including one of two of the anonymous reviewers for this paper) find (88) unacceptable.

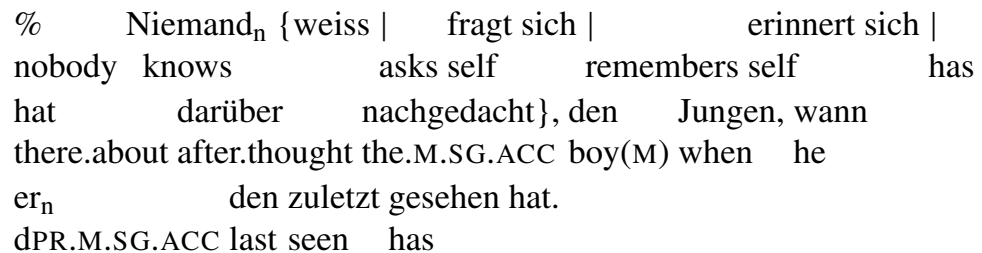

'Nobodyn $\{$ knows|wonders|remembers|has thought about $\}$ when he $\mathrm{n}_{\mathrm{n}}$ last saw the boy.'

Whether (88) is acceptable to a particular speaker or not, ellipsis of the question is categorically impossible for all speakers, (89). Under the present analysis, the source of the swamp construction is contrastive left-dislocation with question ellipsis. As we can see, there are no speakers for whom selected questions make this source available. This lack of a source explains why the swamp construction is not available in selected indirect questions and accounts for the status of example (1c). 


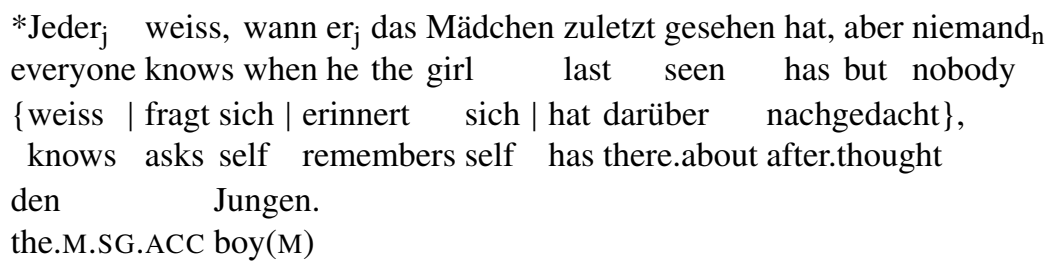

The same categorical ungrammaticality also obtains when contrastive left-dislocation is combined with ellipsis of the question in the other contexts mentioned above: embedded coordination in (90a), extraposed question in (90b), subject question in (90c), and unselected embedded question in (90d). (For further relevant examples demonstrating that contrastive left-dislocation with clausal ellipsis patterns with the swamp construction, see (104)-(111) in Appendix A.)

a. *Die Berichte, dass ich zwar wisse, wer das Mädchen zuletzt the reports that I though know.SBJV who the girl last gesehen hat, aber den Jungen, dass ich das nicht wisse, stören seen has but the boy that I that not know.SBJV annoy mich.

me.

intended: 'The reports that I know who last saw the girl I don't know who last saw the boy annoy me.'

b. *Jede Student-in hat entschieden, der Klara, was every student-F has decided the.F.SG.DAT what she sie der zum Abschied schenkt, aber keine dPR.F.SG.DAT to.the good-bye give.as.present but no student-F Student-in hat bisher da-r-über nachgedacht, dem has so.far there-R-about thought the.M.DAT.SG Hans(M) Hans.

c. *Wer die Mädchen begleitet ist klar, aber die Jungen hängt noch who the girls accompanies is clear but the boys depends still von vielen Unbekannten ab. from many unknowns PRT

d. *Jeder hat erzählt, wem er seine Zeichnung von Brandt geben everybody has told who he his drawing of Brandt give will, aber niemand $\mathrm{n}_{\mathrm{n}}$ hat verraten, seine $_{\mathrm{n}}$ Zeichnung von wants but nobody has disclosed his.F.SG.ACC drawing(F) of Kohl.

Kohl

Without ellipsis of the question, contrastive left-dislocation to the edge of the question in the examples above is sometimes more and sometimes less marked, again subject to a certain amount of variation. We need not pursue the exact status of such examples without ellipsis since the important observation for us is that contrastive left-dislocation in conjunction with ellipsis of the question is sharply ungrammatical. 
So far, this section has established the following points. German allows contrastive left-dislocation and hanging-topic left-dislocation but not topicalization from questions. Contrastive left-dislocation can in addition co-occur with ellipsis of declarative and interrogative clauses. We have seen that the connectivity effects of contrastive left-dislocation match the embedding properties we observed for the swamp construction in Sect. 2.1 and the distribution of interrogative ellipsis matches that of the swamp construction (Sect. 2). These facts strongly suggest unifying the two phenomena, which is what the current analysis does.

The argumentation in this section up to this point builds entirely on observational parallels between contrastive left-dislocation coupled with question ellipsis on the one hand and the swamp construction (in English and German) on the other hand. We have not committed to a particular analysis of contrastive leftdislocation.

It is worth asking what-if anything - the present analysis of the swamp construction tells us about the theory of contrastive left-dislocation. Four basic lines of analysis can be found in the literature: Contrastive left-dislocation as binding or base-generated chain formation between left dislocate and d-pronoun (Anagnostopoulou 1997; Wiltschko 1997; Frey 2004), (91a); contrastive left-dislocation as movement from an underlying constituent containing left dislocate and d-pronoun (Vat 1981, Grewendorf 2009), (91b); a bi-clausal analysis where the left-dislocate is topicalized in the first clause followed by clausal constituent ellipsis of the first clause under identity with the second clause (Ott 2014, 2015), (91c); and finally a bi-clausal analysis with non-constituent ellipsis of the first clause up to the left dislocate under identity with the second clause (Ott and Struckmeier 2018), (91d). The structure of Ross's example was given above with analysis (91b) in mind.

a.

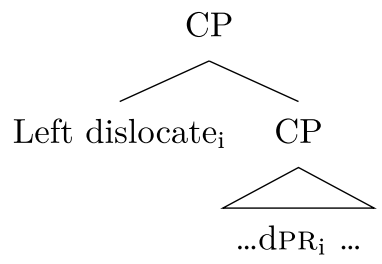

b.

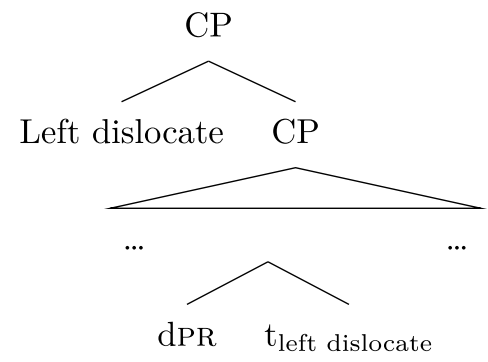


c.

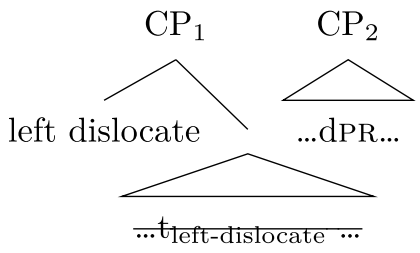

d.

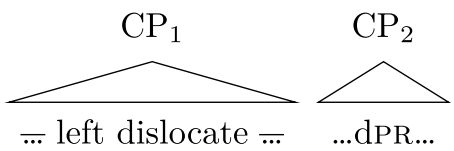

While none of these approaches is entirely without problems, the data discussed here seem most easily compatible with (91a), (91b), and (91d). They do not seem compatible with (91c). This is so, because the approach assumes that topicalization of the left dislocate is the derivational source of contrastive left-dislocation. However, we have seen in the discussion of Abe's account of the swamp construction that there is no match between topicalization and the swamp construction. Recall also that we alluded to a discussion in Altmann (1981) above, (72), where it is observed that CPs in positions where no structural case is assigned cannot be topicalized but must be left-dislocated. Topicalization then cannot, in general, be the source of contrastive left-dislocation.

The remaining three approaches are more or less directly compatible with the present proposal concerning the swamp construction. The approach in (91a) assumes a binding relation or base generated chain relation between the left dislocate and the d-pronoun. The structure of Ross's example under this analysis would be identical to the structure given above (14) and (74) except for the presence of the trace of the left dislocate. Under this analysis, the d-pronoun in $\mathrm{Spec}, \mathrm{CP}_{2}$ carries a $w h$-feature. This feature rather than the feature on the overt $w h$-word who checks the relevant features of interrogative $\mathrm{C}_{2}^{0}$. Under the assumption that $w h$-movement is necessitated by a checking requirement of the complementizer not by a checking requirement of the $w h$-phrase, the $w h$-phrase contained in the left dislocate does not create a syntactic violation. The difficulty for this approach (quite independently of the data discussed here) is how to explain the connectivity between left dislocate and d-pronoun. ${ }^{36}$

Approach (91b) assumes that contrastive left-dislocation is derived from an underlying structure in which the left dislocate and the d-pronoun form a constituent. This approach was chosen for ease of exposition in the structures above. While this approach solves the problems of binding connectivity relatively easily it suffers from a number of other difficulties (see Ott 2014 and references cited there). Again, we would presumably assume that in examples with massive pied-piping the $w h$-word is too far removed from interrogative C to check C's features (Cable 2010), lead-

\footnotetext{
${ }^{36}$ The problem is currently unsolved but it is not restricted to contrastive left-dislocation. Salzmann (2006) shows that there is similar reconstruction into the position of the resumptive pronoun in resumptive prolepsis. In those cases, only binding seems plausible.

Notice also that semantically the correct interpretation for (14) can easily be derived if we assume that the wh-d-pronoun is bound and semantically restricted by the left dislocate. This analysis can be implemented using the semantics for partial $w h$-movement and pied-piping in Sternefeld (2001).
} 
ing to a crash. This syntactic problem is solved in the structure of Ross's example, $(14) /(74)$, by the presence of the $w h$-d-pronoun. This d-pronoun is sufficiently local to the interrogative $\mathrm{C}$ to check its features. ${ }^{37}$

Finally, the approach in (91d) proposes that the left dislocate is in situ with the flanking material undergoing non-constituent ellipsis. While this approach presents an attempt to solve the problems facing the other two approaches, the swamp construction raises its own questions for this approach: The first has to do with the appearance of the $w h$-word within the left dislocate. Under this approach, the structure of Ross's examples would be something like the following:

... but [CP1 I don't know who he has a picture of <who>] [CP2 I don't know wh.dPRhe has] [CP3 dPR I don't know]

$\mathrm{CP}_{2}$ is pronounced as a picture of who, $\mathrm{CP}_{2}$ is elided entirely, and $\mathrm{CP}_{3}$ is pronounced in full. $\mathrm{CP}_{1}$ is a regular contrastive left-dislocation structure where the left dislocate corresponds to a d-pronoun in the following clause. ${ }^{38} \mathrm{CP}_{2}$ and $\mathrm{CP}_{3}$ again are in the appropriate relation on the assumption that the entire complement of know in $\mathrm{CP}_{2}$ would have been the left dislocate, which is found in pronominal form in $\mathrm{CP}_{3}$-with a null realization in English. A direct pairing of $\mathrm{CP}_{1}$ with $\mathrm{CP}_{3}$ without the mediation of the completely silent $\mathrm{CP}_{2}$ leads to an incongruent contrastive left-dislocation structure because the left dislocate a picture of who does not match the d-pronoun, which stands for the entire $\mathrm{CP}{ }^{39}$

The most immediate problem of this approach raised by the swamp construction has to do with the position of the wh-word. Who will normally have moved to Spec,CP and is thus not realized within the DP a picture of who. The question arises why the in-situ realization is possible just in case the rest of the clause is elided? While this issue needs some attention, it seems relatively straightforward in principle under the copy theory of movement. A second, related, question has to do with the $w h$-feature of the head of the indirect question in $\mathrm{CP}_{1}$. This issue is particularly acute in the German rendition of Abe's example, (11a). Two possible versions are given below (in English translation for simplicity). Neither of the two versions of $\mathrm{CP}_{1}$ in (93) is acceptable in German. (93a) is a violation of the adjunct island condition. (93b) involves illicit massive pied-piping. ${ }^{40}$

\footnotetext{
${ }^{37}$ Again the semantics of the construction can be captured directly: the left-dislocate must be interpreted in the position of its lower copy which then gives rise to a standard (massive) pied-piping configuration, which is semantically straightforward (see Sternefeld 2001; Cable 2007).

${ }^{38}$ Ott (2014) argues that contrastive left-dislocation doesn't actually require a d-pronoun but that any suitable form works. This leads to the expectation here that the following should be a well formed contrastive left-dislocation structure:

Ein Buch über wen, was hat er gekauft?

a book about who what has he bought

The example strikes me a fairly deviant. I will not pursue the question here why this might be so and whether the observation can be made to follow from Ott's approach.

${ }^{39}$ Nothing in what follows rests crucially on the presence of $\mathrm{CP}_{2}$.

${ }^{40}$ The data reported in Kotek and Erlewine (2016) suggest that covert $w h$-movement does allow and indeed favor pied-piping of the picture of who type found in Ross's example but the data in Kotek (2015) suggest that covert $w h$-movement does not allow pied-piping of islands.
} 
a. ... but [CP1 I don't know what he spend the entire day at the mall in order to achieve]

b. ... but [CP1 I don't know in order to achieve what he spent the entire dat the mall]

Both alternatives are somewhat fraught. These issues would need to be addressed carefully, for a successful implementation of the current analysis of the swamp construction in terms of (91d).

To wrap up, this section has shown that the distribution and the reconstructive behavior of contrastive left-dislocation with question ellipsis (in German) mirrors the distribution and the reconstructive behavior of the swamp construction (in English). The data reported throughout and in Appendix A extend the parallel further to the swamp construction in German. Given that contrastive left-dislocation with clausal ellipsis is available in German anyway, the only obstacles to the analysis proposed here (for German) come from the observations that (phrases containing) wh-pronouns (not scoped within the left dislocate) cannot usually be left dislocated and that clausal ellipsis is generally optional in the contexts where it is allowed. For English a bit more work is needed. We will need to address the question of why the d-pronoun corresponding to the fronted CP cannot be realized in English and why, more generally, English does not generally seem to have a contrastive left-dislocation structure of the German type while exhibiting it in the swamp construction.

\section{Morphological assumptions}

This section is divided into two parts. in the first part, I address the question of why ellipsis of $\mathrm{CP}_{2}$ in (14) is obligatory. Here, I adopt the idea from Kennedy and Merchant (2000), Merchant (2001), Kennedy (2003) that morphological gaps can be repaired by phrasal ellipsis and can force ellipsis. The second part will make some of the assumptions more explicit that are needed to transfer the analysis from German, where all of this is relatively straightforward, to English.

\subsection{Obligatory clausal ellipsis}

The issue to be addressed in this subsection is the question of why ellipsis is obligatory in the swamp construction. The full structure is syntactically well-formed. So why can it not be pronounced? The leading idea I use to answer this question comes from Kennedy and Merchant (2000), Merchant (2001), Kennedy (2003), who suggest that the morphology, the lexicon of a language, can sometimes force ellipsis.

Before turning to the question of how to explain why ellipsis is obligatory in the swamp construction, it is worth briefly considering whether the possibility of clausal ellipsis in non-wh-examples of left-dislocation with clausal ellipsis is anomalous. Specifically, an anonymous reviewer raises the question of whether there are other documented cases where entire CPs are elided, as my analysis demands. The distribution on ellipsis, as we saw, is determined only in part by the internal syntax of the elided clause-left-dislocation is required within the clause-but also by its external distribution - the clause itself must be a root or left dislocated. This dependency on 
the external distribution suggests strongly that the ellipsis licensor is not the sister of the elliptical constituent. Aelbrecht (2010) argues in detail that ellipsis licensors are not always the sister of the elided phrase. Are there other examples of CP ellipsis specifically, where the ellipsis licensor is external to the CP. Such ellipsis has been argued to exist in Japanese in the form of argument ellipsis (see Takahashi 2013; Sakamoto 2017; Takita 2018; and references cited there). ${ }^{41}$ Likewise, Collins (2015) proposes that there is an operation of relative clause deletion in English which elides the entire CP. Finally, there is no reason I am aware of to assume that topic drop constructions in German do not apply to CPs. A potential example is given below. In the example, the complement of the verb glauben-'believe' can be dropped in B's answer from the clause initial position under topic drop. Clearly, topic drop is an externally licensed ellipsis phenomenon. Alas, this is not an unambiguous example, since the complement can be realized either as a CP or as a DP. I know of no reason to suspect that dropping the $\mathrm{CP}$ is impossible. However, since the ambiguity seen here is pervasive, indirect argumentation would be necessary to establish that topic drop of CPs is allowed, a task I will not undertake here.
A: Glaubst du, dass Gott die Welt erschaffen hat? believe you that god the world created has 'Do you believe that God created the world?'

B: Nee. $\{$ Dass Gott die Welt erschaffen hat, Idas $\mid \emptyset\}$ glaube ich nicht. no that god the world created has that believe I not. 'No. I don't believe $\{$ that God created the world I that $\}$.'

Assuming then that $\mathrm{CP}$ ellipsis is available in principle, we can move on to the question of why it is obligatory in the swamp construction.

My reasoning is based on Kennedy and Merchant (2000), Merchant (2001), Kennedy (2003). These papers discuss the following type of data. They observe that (95a) is ungrammatical because of a left-branch violation and that (95b) is grammatical and is interpreted as though it had the structure in (95c), which again violates the left branch condition.
a. *The Cubs start a more talented infield than the Sox start an outfield.
b. The Cubs start a more talented infield than the Sox do.
c. The Cubs start a more talented infield $\mathrm{OP}_{\mathrm{i}}$ [than the Sox do EvP start [DP an $t_{i}$ inflield].

In view of the fact that other languages do allow left branch extraction and guided by the idea that linguistic variation is ultimately lexical, Kennedy and Merchant propose that languages that allow left branch extraction overtly do but languages that do

${ }^{41}$ E. Panitz (p.c.) informs me that there are speakers of Brazilian Portuguese who accept sentences like the following:

$$
\begin{aligned}
& \text { Essa bicicleta a Maria forçou alguém a lavar. Aquela bicicleta, a Clara forçou alguém. } \\
& \text { this bike the Maria forced someone to wash. That bicycle the Clara forced someone } \\
& \text { 'Maria forced someone to wash this bike. Clara forced someone to wash that bike.' }
\end{aligned}
$$

Assuming that the control clause is a $\mathrm{CP}$, these data exemplify extraction from the elided complement CP. See Panitz (2017) for discussion of why examples like these have no parse as verb stranding VP ellipsis. 
not allow it do not have a morpheme that allows extraction of DegP from the edge of DP. The relevant notion of a morpheme is (roughly) that of a stable correspondence between a bundle of syntactic/semantic features and a phonological representation (which might, of course, be null). The proposal is that left branch extraction is impossible in the general case because English has a morphological gap. This gap prevents the structure underlying both (95a) and (95b) from being pronounced fully. But in (95b) ellipsis bleeds lexical insertion. Thus, the morphological gap remains undetectable to the system and the derivation converges.

In late lexical insertion models (like distributed morphology or nano-syntax) this is a plausible and natural approach. Feature bundles that have no realization according to the lexicon of the language will lead to morphological crash. Because the syntax is oblivious to lexical vagaries of this sort, ineffability of the corresponding syntactic structure results even if the syntactic structure itself is well-formed. But if the system never needs to attempt insertion, morphological crash can be avoided. ${ }^{42}$

Arguably, this is also what happens with a class of defective verbs in Russian which lack first person singular non-past forms. This fact is illustrated in the following table for the two verbs buzit'-'make a fuss' and šelestet'-'rustle' (extracted from Baerman et al. 2009 with similar non-defective verbs for comparison).

\begin{tabular}{l|ll|ll} 
& \multicolumn{3}{|c}{$\mathrm{z}-\mathrm{z}$} & \multicolumn{2}{c}{ st - šč } \\
& $\begin{array}{l}\text { buzit' } \\
\text { 'make a fuss' }\end{array}$ & $\begin{array}{l}\text { porazit' } \\
\text { 'strike' }\end{array}$ & šelestet' & pustit' \\
'rustle' & 'release' \\
\hline $1^{\text {st }} \mathrm{SG}$ & - & poražu & & \\
$2^{\text {nd }} \mathrm{SG}$ & buziš' & poraziš' & šelestiš' & pušču \\
$3^{r d} \mathrm{SG}$ & buzit & porazit & šelestit & pustit \\
$1^{\text {st }} \mathrm{PL}$ & buzim & porazim & šelestim & pustim \\
$2^{\text {nd }} \mathrm{PL}$ & buzite & porazite & šelestite & pustite \\
$3^{r d} \mathrm{PL}$ & buzjat & porazjat & šelestjat & pustjat
\end{tabular}

Of course, there are presumably well-formed syntactic structures that would require the absent forms, but they are ineffable.

We saw that Kennedy and Merchant (2000) suggest that the effect of ineffability caused by morphological gaps can be repaired by ellipsis. This follows quite directly if we assume that elliptical structures do not require morphological insertion at the ellipsis site. We can now test this idea by observing how the defective Russian verbs behave under ellipsis. The examples here involve stripping (E. Titov, N. Slioussar, p.c.):

$$
\begin{aligned}
& \text { On }\{\text { buzit } \mid \text { šelestit }\} \text { a ja net. } \\
& \text { he makes.a.fuss rustles, but I not } \\
& \text { 'He }\{\text { makes a fuss } \mid \text { rustles }\} \text { but me not.' }
\end{aligned}
$$

\footnotetext{
${ }^{42}$ What matters to me here is the logic of the account not whether it is the correct approach to left branch extraction. There are in fact reasons to believe that ellipsis does not repair violations of the left branch condition (Grebenyova 2006; Barros et al. 2014), making an account of Kennedy and Merchant's data in terms of the interplay of covert movement and pied-piping along the lines of Kennedy (2002) more appealing.
} 
On the assumption that stripping derives from syntactically full fledged but elliptical structure, these examples confirm Kennedy and Merchant's conjecture: The ineffability of I \{make a fuss | rustle\}., caused by a morphological gap, is repaired by ellipsis. Descriptively, ellipsis is obligatory with verbs like buzit' and šelestet' when the subject is first person singular. Of course, ellipsis needs to be available independently, as it is in the case of stripping above.

The claim that a morphological gap makes otherwise optional ellipsis obligatory needs to be distinguished from the following alternatives: (i) The relevant form is phonologically null; (ii) the morphological gap licenses ellipsis of the relevant head; (iii) the morphological gap licenses ellipsis of a constituent containing the head. All three of these alternatives overgenerate in obvious ways: (i) predicts that the null verb should act like a regular verbal form so that ja // should be able to mean I rustle or I make a fuss independently of context; (ii) and (iii) predict that in contexts where ellipsis is not usually available, the occurrence of the lexical gap should allow it. Contrary to this expectation, the translation of I complain and. into Russian is as incomplete as it is in English and does not mean I complain and make a fuss. The reason (97) is grammatical is not because the morphological gap licenses ellipsis. It does not. The example is grammatical because there is an independent ellipsis process, stripping, which can occur here. Not applying this independently available process with the missing verb forms leads to a crash; thus, ellipsis must apply. All of this is quite natural, if we assume that ellipsis bleeds lexical insertion.

The interaction between the (distributed) lexicon and ellipsis is a principled case of repair by ellipsis. The existence of such cases can be deduced directly from the nature of ellipsis under the independently motivated architectural assumption of late lexical insertion. Unlike literal island repair by ellipsis, which is completely ad hoc (Culicover and Jackendoff 2005), there is nothing ad hoc or mysterious about the idea of repairing lexical gaps by ellipsis.

I propose that this type of explanation should be given to the puzzle of why clausal ellipsis under contrastive left-dislocation becomes obligatory in the swamp construction: The sister of the Q-morpheme in (14) has simultaneous properties of a wh-word and of a bound d-pronoun. ${ }^{43}$ On the assumption that neither English nor German have the relevant morpheme in their lexicon, the non-elliptical version of $\mathrm{CP}_{2}$ is ineffable. Recall from the discussion immediately above that morphological gaps are not themselves ellipsis licensers; morphological gaps will make independently available ellipsis obligatory. What candidate elliptical processes are there? There is no process eliding $w h$-phrases in Spec, $\mathrm{CP}$ in German. Therefore, any elliptical process saving CLD-P $\mathrm{P}_{2}$ (and every phrase containing it) from ineffability will minimally have to target $\mathrm{CP}_{2}$ - and this, thanks to the independent availability of contrastive leftdislocation with clausal ellipsis in the relevant environments, is exactly what we find.

For German, all we need to assume is that it lacks a wh.dPR morphologically to explain why question ellipsis is obligatory in the swamp construction but optional otherwise. This approach predicts that there could be a language that is just like German in all respects except that it does have a morphological exponent for wh.dPR.

${ }^{43} \mathrm{~A}$ reviewer asks whether the relative pronoun der is not a lexicalization of $w h . \mathrm{dPR}$. There is no reason to think that this is so, since der never satisfies the $w h$-feature of interrogative $\mathrm{C}$. 
This language would be expected to have an elliptical as well as a non-elliptical version of the swamp construction.

\subsection{Back to English}

The question to be addressed in this part of the paper is the following. How can English possess the swamp construction without having contrastive left-dislocation more generally? Given that the structure for Ross's example proposed here involves two instances of contrastive left-dislocation, I will discuss the solution for each of these cases separately.

It should be clear that the current analysis of contrastive left-dislocation with question ellipsis and of the swamp construction in German can be carried over to English only if we assume that the $w h$-phrase with apparent massive pied-piping is really left dislocated. That is, we have to assume that the structure of CLD-P 2 is the same in German and in English. We will have to assume that $\mathrm{CP}_{2}$ can be elided in the relevant cases and that ellipsis is forced here specifically because English has the same morphological gap as German: it lacks a wh-d-pronoun.

Independent support for the existence of contrastive left dislocation with question ellipsis might come from examples like the following:

We know who last saw the girl. But the boy? That we don't know.

I have not studied such examples sufficiently to know whether they truly involve an embedding structure and support connectivity effects for the putative left dislocate the boy as they should, if they correspond structurally to (13b).

It seems to me that my approach to Ross's example forces me into the position that the massively pied-piped ellipsis remnant is contrastively left-dislocated and that the corresponding CP is elided, obligatorily so because of the morphological gap. ${ }^{44}$

This leaves the second instance of contrastive left-dislocation indicated in structure (14)/(74). While German provides strong evidence from the presence of the dpronoun that CLD-P $\mathrm{P}_{2}$ is left dislocated rather than topicalized from $\mathrm{CP}_{1}$, the evidence from the English swamp construction does not overtly suggest this conclusion. Indeed, CLD-P 2 could just as well have been topicalized and we could easily claim that in English it is. This would lead to the idea that English has no overt (nonelliptical) contrastive left-dislocation at all. The entire series of d-pronouns are morphological gaps in English, hence contrastive left-dislocation only exists in elliptical form. ${ }^{45}$

\footnotetext{
${ }^{44}$ Though I cannot pursue this issue here, one might speculate that fragment answers in English are derived from contrastive left-dislocation with ellipsis. This would provide a second example in English of contrastive left-dislocation with clausal ellipsis. The main challenge to overcome are almost certainly the arguments against a derivation of fragments in terms of syntactic movement given in Weir (2014).

${ }^{45}$ Such an analysis where CLD- $\mathrm{P}_{2}$ is topicalized does not contravene the distributional arguments given above. In Sect. 2 argued that the swamp construction does not have the distribution of topicalization. The arguments proposed there are compatible with the hypothesis discussed here. The root cases of the swamp construction will still only involve contrastive left-dislocation with ellipsis and not involve topicalization. Ross's example will require both topicalization (of CLD- $\mathrm{P}_{2}$ ) and ellipsis (of $\mathrm{CP}_{2}$ ). We would have to say that the conjunction of these two processes is possible in English only in the same, restricted environments where recursive contrastive left-dislocation with question ellipsis is possible in German - presumably for similar reasons.
} 
An alternative approach to the hypothesized contrastive left-dislocation of CLD- $\mathrm{P}_{2}$ might be to suggest that English allows contrastive left-dislocation of clauses - and maybe other categories (see Ott 2017 for discussion of English VPtopicalization in this spirit)—but that the d-pronouns are phonologically null. The idea that CPs are left dislocated with a null pronoun in English is not at all new. The existence of a null pronoun resuming a displaced clause has long been hypothesized (Koster 1978; Alrenga 2005). The fact that there seems to be a systematic category mismatch between fronted CPs and their gaps, (99)-(101), suggests as much.

(Bresnan 2001:17, ex. (3))

a. That he was sick we talked about for days.

b. *We talked about that he was sick for days.

c. We talked about the fact that he was sick for days.

(100) (Moulton 2015:306, ex. (3))

a. Albert $\{$ boasted $\mid$ commented $\mid$ complained $\}$ that the results were fantastic.

b. *Albert $\{$ boasted | commented | complained $\}$ \{that $\mid$ it $\mid$ a belief that the results were fantastic $\}$.

c. *That the results were fantastic, Albert \{boasted | commented | complained $\}$.

(101) (Williams 2016:2, ex. (4))

a. *That John is here I was not aware.

b. That John is here I was not aware of.

c. I was not aware (*of) that John is here.

The category mismatch could be the result of the categorial status of d-pronouns as DPs in English together with the idea that CPs are never topicalized and always contrastively left-dislocated in English (for relevant discussion of connectivity effects see Moulton 2015). ${ }^{46}$

There is clearly more work to be done here, but it seems plausible that one of the ideas above about contrastive left-dislocation in English will find independent support. Like German, English lacks a morphological exponent for the wh.dPR and like English, in the restricted environments where we find the swamp construction, contrastive left-dislocation can be coupled with clausal ellipsis. Assuming this much, the analysis of German will carry over to English.

It is natural to ask at this point whether it would not be more economical to assume that the swamp construction is an instance of sluicing after all and to replace the assumptions made here by the following set of assumptions: There is a wh-complementizer which is endowed with (i) the E-feature, (ii) a feature that forces fronting of the clause projected by this head, and (iii) a flavor of the $w h$-feature that allows massive pied-piping. This $\mathrm{C}$-head encodes through feature conjunction the properties of the swamp construction. Given that the conjunction of features is arbitrary, this account leads naturally to the assumption that $\mathrm{C}$ heads with any of the

\footnotetext{
${ }^{46}$ We saw above, (72), that German transparently disallows topicalization of CPs in oblique cases and forces those CPs to contrastively left-dislocate. English might have generalized this ban against CP topicalization to all environments.
} 
combinations of properties (i)-(iii) should be able to exist. In particular, we should be able to find languages with $\mathrm{C}$ heads instantiating just (i) and (iii). This would be a language which obeys certain constraints on pied-piping in regular wh-questions but where these constraints are inoperative under sluicing. I would take the existence of such a language to falsify the wh-move-and-delete approach to sluicing; such a language would violate the fundamental corollary of all wh-move-and-delete analyses discussed above: "Only those constituents that can occupy Spec,CP in full $w h$-questions can be sluicing remnants." 47 Given that this corollary of all wh-moveand-delete approaches is extremely well supported, there is clear evidence that the alternative theory sketched in this paragraph is incorrect.

Let me briefly draw a conclusion. In this section, I have discussed two open issues. The first subsection took the idea as given that the swamp construction in German is an instance of contrastive left-dislocation and suggested a way to relate the two exceptional properties of the swamp construction to each other: the fact that the left dislocate contains a $w h$-word and the fact that clausal ellipsis is obligatory. I suggested that ellipsis is obligatory because the non-elliptical version of the swamp construction would require a wh.dPR, but the lexicon of German does not contain such an item. The second and more speculative subsection briefly sketched the additional assumptions needed to apply the analysis developed for German to English. No attempt was made to defend these assumptions any further or choose between the different versions briefly entertained above.

\section{Conclusions and outlook}

This paper has proposed an analysis of Ross's example (1a) with four key ingredients: (i) The analysis involves contrastive left-dislocation. (ii) It invokes contrastive leftdislocation from a question. (iii) It capitalizes on the possibility of eliding a clause that has itself been dislocated from in certain environments. (iv) Finally, it invokes contrastive left-dislocation of a phrase containing an unscoped $w h$-word. (i)-(iii) are independently available in German. The assumption in (iv) does not raise any interpretive difficulties (see fn. 36 and 37). But I suggested that the lack of a morphological exponent of the wh.dPR explains why ellipsis is obligatory. The analysis is extremely well supported for German. Somewhat speculatively, I suggest that it should be applied to English as well.

Descriptively, the paper offers the first in depth study of the swamp construction in German and English as well as the first detailed description of left-dislocation with ellipsis of an interrogative clause.

Analytically, we have seen that neither Bechhofer's nor Abe's analyses of the swamp construction are adequate and should be given up. Abe suggests that the success of his approach in deriving an analysis of the swamp construction furnishes a

\footnotetext{
${ }^{47}$ The other two combinations of features are either relatively innocuous or hard to distinguish from the current proposal. A language that had a $\mathrm{C}$ head with (i) and (ii) but without (iii) would allow sluicing under clausal fronting, which isn't particularly shocking. If the language in addition lacked a head instantiating (i) it would allow sluicing only under fronting. A language that had a $\mathrm{C}$ head with (ii) and (iii) but without (i) would be very similar to the language type with a morphological exponent of the wh.dPR whose existence is predicted here.
} 
strong argument for his in-situ approach to sluicing. The fact that his analysis of the swamp construction, an analysis which he claims follows naturally from his general view of sluicing, is fundamentally flawed should probably then count as an argument against his general view.

The theoretical ramifications do not stop here, of course. We saw in the introduction that $w h$-move-and-delete accounts of sluicing derive the corollary that only wh-moveable constituents can be sluicing remnants. Wh-move-and-delete analyses can be contrasted with semantic/pragmatic approaches. The latter typically adhere to a what-you-hear-is-what-you-get philosophy and posit no (contextually variable) syntactic structure at the ellipsis site and, in particular, no wh-movement within the ellipsis site. Such theories do not derive the corollary that only wh-moveable constituents can be sluicing remnants. Instead, they have as their fundamental corollary that (all and) only constituents that can be interpreted as wh-phrases can be sluicing remnants. The classes of constituents picked out as potential sluicing remnants in the two types of theories are different. Cross-linguistic work on pied-piping (see for example Heck 2008; Cable 2010) has always suggested that interpretability is too weak a constraint to capture constraints on sluicing remnants. The swamp construction drives this point home: The DP remnant in Ross's example (1a) and the VP remnant in Abe's example (6a) can give rise to a question interpretation quite easily, yet, they are not possible sluicing remnants. It is difficult to see how semantic/pragmatic approaches to ellipsis can deal with these facts without adopting many of the assumptions of $w h$-move-and-delete approaches to ellipsis.

To conclude, I would like to mention three directions in which this analysis might be extended and a number of open questions. First, it seems like an interesting question to ask if (some or all) fragments can be analyzed as cases of contrastive leftdislocation with clausal ellipsis (see Ott 2015:273, fn. 54 for relevant discussion). The largest immediate stumbling block for such an extension are the kinds of facts discussed in Weir (2014: Chap. 4) as arguments for the PF-movement analysis of fragments. ${ }^{48}$

Second, there is a fairly good correspondence between contrastive left-dislocation and right dislocation in German. However, while contrastive left-dislocation is restricted to d-pronouns as resumptive elements, right dislocation is not. Right dislocation also occurs with regular pronouns and full noun phrases:

\{Den | Ihn | Den Typen da drüben $\}$ kenne ich gut, den
that.M.SG.ACC him the guy there yonder know I well the
Mann aus Wiesbaden.
man from Wiesbaden
'I know \{him | the guy over there $\}$ well, the man from Wiesbaden.'

Given the general correspondence between contrastive left-dislocation and right dislocation, one might wonder whether there are also right dislocation versions of the swamp construction. Of course, right and left-dislocation with clausal ellipsis are very difficult if not impossible to distinguish. However, since there is no requirement

\footnotetext{
${ }^{48} \mathrm{~A}$ contrastive left-dislocation analysis of fragments is immediately compatible, however, with evidence for overt movement in fragment answers (see Shen 2018), and with connectivity effects.
} 
for a d-pronoun to appear in right dislocation structures, we might expect to be able to construct non-elliptical versions with regular wh-phrases. It would then be interesting to probe the acceptability, distribution, and interpretation of structures like the following to assess whether these might be the non-elliptical right dislocation variants of the swamp construction: ${ }^{49}$

a. Ich frage mich, was er gekauft hat, ein Bild von wem.

I wonder self what he bought has a picture of who 'I wonder what he bought, a picture of who.'

b. Er war den ganzen Tag im Einkaufszentrum. I frage mich, he was the whole day in.the mall I wonder self warum er da war, um dort was zu erledigen. why he there was in.order there what to achieve 'He was the whole day at the mall. I wonder why he was there, to achieve what.'

Finally, the question of the cross-linguistic distribution of the swamp construction arises. Do other languages have the swamp construction? Does the swamp construction in those languages also show signs of being left-dislocation in disguise? A first hint that this might be so comes from Spanish and Swedish. In both languages, renditions of Ross's example are possible but require left-dislocation of the interrogative clause. This is marked by a d-pronoun in Swedish and a clitic in Spanish.

There are also a number of open questions for the analysis itself. Notably, the present account is built on the correlation between the contexts for contrastive left dislocation with question ellipsis and contexts for the swamp construction. While the correlation seems empirically solid, this is not a theory of contrastive left-dislocation with question ellipsis. Such a theory will need to identify theoretically the licensing condition for this peculiar type of clausal ellipsis. Secondly, the issue raised in fn. 5 needs to be addressed: How come clausal ellipsis of the question is possible despite the fact that the overt counterpart question contains an obligatorily stressed d-pronoun. Finally, which of the ways of applying the analysis to English hinted at in Sect. 5.2 best fits the facts?

This paper has two appendices. The first appendix provides data concerning the swamp construction in German both with nominal and with verbal remnants. They are given side-by-side with corresponding examples of contrastive left-dislocation with question ellipsis. The appendix establishes nearly identical behavior between the German and the English swamp constructions, which is, of course, what the current analysis predicts. Both the nominal and the verbal versions of the data are presented to ward against the worry that speakers with more liberal pied-piping might otherwise feel. The second appendix discusses Abe's in-situ theory of sluicing with the particular aim to assess whether Abe derives the generalization that only wh-movable constituents can be sluicing remnants. The conclusion is negative.

\footnotetext{
${ }^{49}$ The examples would need to be carefully distinguished from Ott and de Vries (2016:650, ex. (21)) which shows regular sluicing within a right-dislocated question.
} 
Acknowledgements I would like to thank Jason Merchant, Dennis Ott, Luisa Martí, Bjørn Lundquist, Andreas Haida-Sorry, Andreas! The semantics disappeared from this version-and two anonymous NLLT reviewers for their useful comments that helped me clarify many points and forced me to think more carefully about a number of issues. I am indebted to the participants of my courses on ellipsis at the HUJI/TAU Winter School in Syntax (Jerusalem) and of my advanced syntax course at UCL for useful discussion. Finally, I would like to acknowledge the audiences in Leipzig, London, Alcalá, Trondheim, and Chicago for their interest, questions, and comments.

Open Access This article is distributed under the terms of the Creative Commons Attribution 4.0 International License (http://creativecommons.org/licenses/by/4.0/), which permits unrestricted use, distribution, and reproduction in any medium, provided you give appropriate credit to the original author(s) and the source, provide a link to the Creative Commons license, and indicate if changes were made.

\section{Appendix A: The swamp construction in German}

\section{A.1 The distribution of the swamp construction and of contrastive left-dislocation with question ellipsis in German}

We first look at some basic distributional facts concerning the swamp construction in German and match them up with the distribution of left-dislocation with question ellipsis. To the extent possible, the data are parallel to the English data in Sect. 2.

(104) Swamp under embedded coordination (compare (20))

a. *Die Meldungen, dass wir zwar wissen, dass er den the reports that we although know.SBJV that the the Steckbrief von jemandem hat, aber den Steckbrief von wem, wanted.poster of somebody has but the wanted poster of dass wir das nicht wissen, beunruhigen mich. who that we that not know.SBJV worry me

b. *Die Meldungen, dass er den ganzen Tag im Einkaufszentrum the claims that he the whole day in.the mall

gewesen sei, um dort etwas zu erledigen, aber um been is.SBJV in.order there something to achieve but in.order dort was zu erledigen, dass ich das nicht wisse, there what to achieve that I dPR.N.SG.ACC not know.SBJV beunruhigen mich. worry me

(105) Left dislocation with question ellipsis under embedded coordination (compare (20))

a. *Die Meldungen, dass ich zwar wisse, wer den Steckbrief the reports that I though know.SBJV who the wanted.poster von Helmut Kohl hat, aber den (Steckbrief) von Angela Merkel, of Helmut Kohl has but that wanted.poster of Angela Merkel dass ich das nicht wisse, stören mich. that I dPR.N.SG.ACC not know.SBJV annoy me 
b. *Die Meldungen, dass ich zwar wisse, wer den ganzen Tag the reports that I though know.SBJV who the entire day im Einkaufszentrum war, um dort Bücher zu verkaufen, aber in.the mall was in.order there books to sell but um dort Tee zu verkaufen, dass ich das nicht in.order there tea to sell that I dPR.N.SG.ACC not wisse, stören mich.

know.SBJV annoy me

(106) Swamp in clausal subjects in the mittelfeld (compare (21))

a. *Wir wissen, dass er ein Bild von jemandem verbrannt hat. Die we know that he a picture of somebody burnt has the weiteren Ermittlung wird, ein Bild von wem, stark further investigation will a picture of who strongly beeinflussen. influence

b. *Der Verdächtige war den ganzen Tag im Einkaufszentrum, the suspect was the entire day in.the mall um dort etwas zu erledigen. Die weiteren Ermittlungen in.order there something to achieve the further investigations hat um dort was zu tun stark beeinflusst. has in.order there what to do strongly influenced

(107) Left dislocation with question ellipsis with clausal subject in the mittelfeld (compare (21))

a. *Die Ermittlungen hat, wer das Mädchen zuletzt gesehen hat, nicht the investigations has who the girl last seen has not sehr beeinflusst, aber ihren Gang hat, den Jungen, stark very influenced but their progress has the boy strongly beeinflusst. influenced

b. *Die Ermittlungen hat, wer im Einkaufszentrum war, um the investigations has who in.the mall was in.order einzukaufen nicht sehr beeinflusst, aber ihren Gang hat, um to.shop not very influenced but their progress has in.order Freunde zu treffen, stark beeinflusst. friends to meet strongly influenced

(108) Swamp with extraposed subject clauses (compare (22))

a. ??Er hat im Einkaufszentrum ein Bild von jemandem gekauft. he has in.the mall a picture of someone bought Für mich ist es vor allem überraschend, ein Bild von wem. for me is it before all surprising a picture of who 
b. *Er war den ganzen Tag im Einkaufszentrum, um dort he was the entire day in.the mall in.order there etwas zu erledigen, aber es ist ziemlich überraschend, um something to achieve but it is rather surprising in.order dort was zu erledigen.

there what to achieve

(109) Left dislocation with question ellipsis with extraposed subject clause (compare (22))

a. *Es war nicht besonders aufschlussreich, wer im

it was not particularly revealing who in.the

Einkaufszentrum ein Bild von Kohl gekauft hat, aber es war schon mall a picture of Kohl bought has but it was rather interessant, ein Bild von Merkel. interesting a picture of Merkel

b. *Wer im Einkaufszentrum war, um dort Bücher zu kaufen, who in.the mall was in.order there books to buy war nicht besonders aufschlussreich, aber es war schon interessant, was not particularly revealing but it was rather interesting um dort Freunde zu treffen.

in.order there friends to meet

(110) Swamp in unselected embedded question (compare (23))

a. ?Hans hat im Einkaufszentrum ein Bild von jemandem gekauft, Hans has in.the mall a picture of someone bought aber die Kassiererin wollte uns nicht verraten, ein Bild von wem. but the cashier(F) wanted us not tell a picture of who

b. ?*Hans war den ganzen Tag im Einkaufszentrum, um dort Hans was the entire day in.the mall in.order there etwas zu erledigen, aber der Wachmann wollte mir nicht something to achieve but the guard.man wanted me not verraten, um dort was zu erledigen. tell in.order there what to achieve

(111) Left dislocation with question ellipsis in unselected embedded question (compare (23))

a. *Die Kassiererin hat uns zwar verraten welche Kunden ein the cashier(F) has us though told which customers a Bild von Kohl gekauft haben, aber sie wollte uns nicht verraten, picture of Kohl bought have but she wanted us not tell ein Bild von Merkel. a picture of Merkel 
b. *Der Wachmann hat uns zwar verraten, wer im the guard.man has us though told who in.the Einkaufszentrum war um dort Bücher zu kaufen, aber er mall was in.order there books to buy but he wollte uns nicht verraten, um dort Freunde zu treffen. wanted us not tell in.order there friends to meet

The patterns above show that the distribution of the swamp construction and of leftdislocation with question ellipsis is very parallel, especially when we look at the more egregious pied-piping violations with in order to.

\section{A.2 Embedding diagnostics}

Next we turn to embedding diagnostics providing data parallel to those discussed in Sect. 3.1. Binding into the elliptical question is possible in the swamp construction and in left-dislocation with elliptical questions.

(112) Binding into question in the swamp construction (compare (45a))

a. Jeder Teilnehmer ${ }_{t}$ muss ein Bild von einem Politiker malen, aber every participant must a picture of a politician paint but ein Bild von welchem Politiker, das weiss noch a picture of which politician dPR.N.ACC.SG known yet keiner $_{\mathrm{t}}$. nobody

'Every participant must paint a picture of a politician but nobody $\mathrm{t}_{\mathrm{t}}$ knows yet which politician he $\mathrm{t}_{\mathrm{t}}$ has to paint a picture of.'

b. Jeder Teilnehmer $r_{t}$ muss den ganzen Tag im Einkaufszentrum every participant must the entire day in.the mall verbringen, um dort etwas bestimmtes zu erledigen, aber spend in.order there something particular to achieve but um dort was zu erledigen, das weiss noch keiner ${ }_{t}$. in.order there what to achieve dPR.N.ACC.SG knows yet nobody 'Every participant must spend the entire day at the mall in order to do something there, but no participant $\mathrm{t}_{\mathrm{t}}$ knows what he $\mathrm{t}_{\mathrm{t}}$ will have to spend the entire day at the mall in order to achieve.'

(113) Binding into question in left-dislocation with question ellipsis (compare (45a))

a. Jeder Zeuge k $_{\mathrm{k}}$ erinnert sich, wann $\mathrm{er}_{\mathrm{k}}$ das Mädchen zuletzt every witness remembers self when he the girl last gesehen hat, aber den Jungen, daran erinnert sich keiner ${ }_{k}$. seen has but the boy there.on remembers self nobody 'Every witness $\mathrm{k}_{\mathrm{k}}$ remembers when he $\mathrm{k}_{\mathrm{k}}$ last saw the girl but nobody $\mathrm{k}_{\mathrm{k}}$ remembers when he $\mathrm{k}_{\mathrm{k}}$ last saw the boy.' 
b. ?Jeder Zeuge e $_{\mathrm{k}}$ erinnert sich, wann er $_{\mathrm{k}}$ im Einkaufszentrum war, every witness remembers self when he in.the mall was

um dort Freunde zu treffen, aber um dort Bücher zu

in.order there friends to meet but in.order there books to

kaufen, daran erinnert sich keiner . $_{\text {. }}$

buy there.on remembers self nobody

'Every witness $s_{\mathrm{k}}$ remembers when he $\mathrm{k}_{\mathrm{k}}$ was at the mall to buy books but nobody remembers when he $_{\mathrm{k}}$ was at the mall in order to meet friends.'

\section{A.3 Category of the fronted constituent}

Concerning the category of the fronted constituent, we saw above (62)-(73) that the swamp construction in German shows clear signs of CP fronting. As a further argument, we can replicate the pattern in (55) in German:

Der Angeklagte war den ganzen Tag im Einkaufszentrum, the accused was the entire day in.the mall um dort etwas zu erledigen.

in.order there something to achieve

a. Um dort was zu tun, fragt sich der Geschworene. in.order there what to do asks self the juror

b. *Um dort was zu tun, findet der Geschworene heraus. in.order there what to do finds the juror out

c. Um dort was zu tun, fragt der Geschworene. in.order there what to do asks the juror

d. *Um dort was zu tun, stellt der Geschworene fest. in.order there what to do set.down the juror fast

Of course, it needs to be shown that in order to clauses can be contrastively left dislocated in German. The following examples show that they can:

(115) Left dislocation of an in order to infinitival clause in declaratives and interrogatives

a. Um Bücher zu kaufen, da musst du ins Einkaufszentrum in.order books to buy there must you in.the mall gehen.

go

'You must go to the mall in order to buy books.'

b. Um bis Mitternacht zu Hause zu sein, wann muss ich da den in.order until midnight to home to be when must I there the Bus nehmen?

bus take

'When do I have to take the bus to make it home by midnight?'

c. Um nach Hause zu kommen, muss ich da den Bus nehmen? in.order to home to come must I there the bus take 'Do I have to take the bus to get home?' 
Pronouns in the left dislocated infinitival clauses can be bound from the matrix, showing that we are dealing with contrastive left-dislocation rather than with hanging topics:

$$
\begin{aligned}
& \text { Ich weiss } \text { wer }_{\mathrm{w}} \text { am Strand war, um } \quad \text { seinen }_{\mathrm{w}} \text { Hund auszuführen, } \\
& \text { I know who at.the beach was in.order his dog to.walk } \\
& \text { aber um } \text { seine }_{\mathrm{w}} \text { Freundin zu treffen, }\left(\text { wer }_{\mathrm{w}}\right. \text { da am Strand war,) } \\
& \text { but in.order his friend(F) to meet who there at.the beach was } \\
& \text { das weiss ich nicht. } \\
& \text { dPR.N.SG.ACC know I not } \\
& \text { 'I know } \text { who }_{\mathrm{w}} \text { was at the beach in order to walk their }{ }_{\mathrm{w}} \text { dog, but I don't }
\end{aligned}
$$

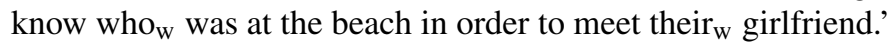

The data reported in this appendix complement those in the main text. Given the data here, even for speakers who tolerate pied-piping of the brother-of-who type in indirect questions and/or sluices, the argument that there is a construction that allows exceptional pied-piping and that it behaves like contrastive left-dislocation with question ellipsis stands.

\section{Appendix B: On the fundamental corollary under Abe's in-situ approach to sluicing}

This appendix provides a systematic look at the proposal contained in chapter 2 of Abe (2015). The chapter contains Abe's core proposal. The main claim I establish is that Abe's approach does not capture the generalization that only those phrases that can undergo wh-movement are possible sluicing remnants. A few comments on chapter 3 about differences between VP ellipsis and sluicing and chapter 4 on the swamp construction will be made where this is pertinent.

I begin these remarks by outlining Abe's proposal again, emphasizing the role of the features driving movement and of those driving pronunciation. I go on to systematically discuss the relation between these two features. The discussion demonstrates that Abe's account of sluicing fails to explain the fact that sluicing remnants are generally $w h$-movable constituents. In other words, I will argue that the following claim (Abe 2015:18) is mistaken: "The present mechanism of movement has one clear advantage $[\ldots]$ : it immediately captures the fact that a possible remnant $w h$-phrase in sluicing corresponds to a possible $w h$-phrase that undergoes $w h$-movement in regular wh-questions."

Under Abe's analysis, as we saw, sluices are CPs with a wh-phrase in Spec,CP, (117). Movement of what is regular wh-movement driven by the feature(s) generally responsible for $w h$-movement. The TP sister of $\mathrm{C}_{\mathrm{Q}}$ is marked '[Delete]' and will be left unpronounced save for material marked '[Focus]'.

$$
\begin{aligned}
& \text { She's reading something, but I can't imagine what. } \\
& {\left[\mathrm{CP}<\text { what }>_{[\text {Focus }]}\left[\mathrm{C}_{\mathrm{Q}}\left[\mathrm{TP}_{[\text {Delete }]} \text { she is reading }<\text { what }>_{[\mathrm{PF}][\text { Focus }]}\right]\right]\right]}
\end{aligned}
$$

Regarding the $w h$-chain, the low copy is pronounced. This is indicated by the markup ' $[\mathrm{PF}]$ ', indicating that the $w h$-phrase's PF-features are located in this position. It is 
the low copy of the wh-phrase which is endowed with PF-features because both links of the chain are adjacent and a high chain link may be pronounced only when high pronunciation has a PF effect.

(118) Condition on high pronunciation (Abe 2015:19, \#44):

Given a chain $\mathrm{C}=\left\{\alpha_{1}, \ldots, \alpha_{\mathrm{n}}\right\}$, the head of each link $\left(\alpha_{\mathrm{i}}, \alpha_{\mathrm{j}}\right)$ cannot be pronounced unless it has an effect on PF output.

Logically, there are six possible geometric relations between the placement of the $w h$-property, henceforth [wh], driving movement and the [Focus] markup:
a. $\quad[w h]$ and [Focus] mark the same XP: $[\mathrm{XP}[w h][$ Focus $] \ldots]$.
b. [Focus] marks XP and $[w h]$ marks YP, where XP irreflexively domi- nates YP: [XP[Focus] ... [YP $[w h] \ldots] \ldots]$.
c. [Focus] marks XP and $[w h]$ marks YP, where YP irreflexively domi- nates XP: $[\mathrm{YP}[w h] \ldots[\mathrm{XP}[$ Focus] $\ldots . . .$.$] .$
d. [wh] is present in the absence of [Focus].
e. [Focus] is present in the absence of $[w h]$.
f. [Focus] on XP and $[w h]$ on YP, where XP neither dominates nor is dominated by YP: $\left[\ldots[\text { XP.... }]_{[\text {Focus }]} \ldots[\text { YP ... }]_{[w h]} \ldots\right]$.

Abe himself offers no systematic discussion of these possibilities and offers no principles restricting the distribution of $[w h]$ and [Focus]. The null assumption is therefore that the relative distribution is of [wh] and [Focus] is free. I discuss the six logical possibilities in turn.

When [wh] and [Focus] mark up the same constituent, this constituent will whmove and be the ellipsis remnant. These are the standard cases of sluicing. The fundamental corollary of $w h$-move-and-delete analyses of sluicing says that this is the only case.

The possibility that the [Focus] markup appears on a phrase properly containing the phrase undergoing wh-movement is allowed by Abe's theory. Abe (2015:18-21) invokes this possibility in his analysis of the swamp construction, which I will not comment on further here, and in his analysis of swiping, (120) (based on Abe 2015:19 \#42):

Lois was talking (to someone), but I don't know who to.

$\left[\mathrm{CP}<\mathrm{who}^{1} \mathrm{C}_{\mathrm{Q}}\right.$ [TP[Delete] Lois was $\left[\mathrm{vP}_{\mathrm{TP}}<\right.$ who $>^{2}$ talking [PP[Focus] $<$ who $>^{3}$ $[\mathrm{PF}]\left[\right.$ [P to ] $\left.\left.\left.\left.\left.<\mathrm{who}>^{4}\right]\right]\right]\right]\right]$

Who moves to Spec, CP but the entire PP is marked as [Focus]. ${ }^{50}$ Therefore, PP survives ellipsis, a phrase properly containing the moving $w h$-phrase. The PF features of who reside in $<w h o>^{3}$, because the initial movement step crosses the preposition and has an effect on PF output while the remaining steps, in the presence of ellipsis, do not. We see then that Abe assumes that the [Focus] markup can reside on phrases properly containing the moving $w h$-phrase. Note furthermore that Abe assumes that [Focus] markup does not necessitate movement of the phrase carrying it: The PP does not move to the left periphery. This conclusion will become important later on.

${ }^{50} \mathrm{Abe}$ also, irrelevantly to the point under discussion, marks who as [Focus]. 
It should be clear that Abe's treatment of swiping opens the door to other structurally similar patterns such as the following:

a. *Lois was talking (to someone), but I don't know who talking to.

b. *Lois said that she talked to someone, but I don't know who that she talked to.

c. *Fred has a picture of someone, but I don't know a picture who of.

d. *Fred has a picture of someone, but I don't know who a picture of.

(121a) simply places [Focus] on vP instead of PP in (120). This saves vP from ellipsis and leads to the pronunciation of 'who' before the remainder of vP. (121b) is a long distance version with CP marked as [Focus] and pronunciation of $<$ who $>$ in the intermediate Spec,CP. (121c-d) are versions of the example with a picture of who as the object and pronunciation of who either at the edge of PP, (121c), or at the edge of DP, (121d). In other words, wherever there is an intermediate landing site, there ought to be a corresponding swipe. This massive violation of the generalization that only whmovable constituents can be sluicing remnants follows directly from Abe's theory.

While Abe does not discuss possibility (119c), nothing seems to rule out the possibility of the phrase undergoing $w h$-movement properly containing the phrase marked [Focus]. Consider the following examples from German, showing that pied-piping is forced in questions about the degree of an attributive adjective as well as their corresponding sluices: ${ }^{51}$

Er hat ein großes Auto gekauft, aber ich weiss nicht, ...

he has a big car bought but I know not

'He has bought a big car, but I don't know...

a. ein wie großes (Auto) (er __ gekauft hat).

a how big car he bought has

how big a car (he bought).'

b. *wie großes (er ein ___ Auto gekauft hat).

how big he a car bought has

c. *wie (er ein __ großes Auto gekauft hat).

how he a big car bought has

(The example is fine on the manner reading of wie-'how', of course.)

It is not clear how Abe would rule out the sluiced versions of (122b-c) $(122 b-c)$. The problematic representations are those where only wie großes-'how big' and wie'how' are marked as [Focus] and survive ellipsis, while the entire DP headed by Auto-'car' moves to Spec,CP in line with the pied-piping requirements of German:

$$
\begin{aligned}
& \text { a. }\left[\mathrm{CP}<[\text { a [how big }]_{[\text {Focus }]} \text { car }\right]_{[w h]}>^{1} \mathrm{C}_{\mathrm{Q}}[\mathrm{TP}[\text { Delete }] \\
& \text { car } \left.\left.]_{[w h]}>^{2} \text { bought has }\right]\right]
\end{aligned}
$$

\footnotetext{
${ }^{51}$ For discussion of apparent left branch extraction see Merchant (2001), Elliott (2012), Barros et al. (2014), Montali (2014), Abels (2018). Such examples crucially involve morphologically predicative adjectives in German, that is, the remnant surfaces with the uninflected adjective wie groß-'how big'. Elliott (2012), Barros et al. (2014), Montali (2014), Abels (2018) provide analyses of such examples that are consistent with the assumptions made in this paper by invoking a copulative clause as the pre-sluice. See (7)-(8) above.
} 
b. $\quad\left[\mathrm{CP}<[\text { a [how }]_{[\text {Focus }]} \text { big car }\right]_{[w h]}>^{1} \mathrm{C}_{\mathrm{Q}}\left[\right.$ TP[Delete] he $<[\text { a [how }]_{[\text {Focus }]}$ big car $]_{[w h]}>^{2}$ bought has]]

Observe that low pronunciation of the wh-chain in (123a) leads to the PF output wie großes-'how big' while high pronunciation of the wh-chain derives either ein Auto wie großes - 'a car how big' or ein wie großes Auto-'a how big car'. Similarly for (123b). Since high versus low pronunciation makes a clear PF difference, one might be tempted to assume that condition (118) would license high pronunciation of the wh-chain, thus correctly ruling out $(123 \mathrm{a}-\mathrm{b})$. However, the notion of what constitutes a PF effect in the sense of (118) is not an intuitive notion in Abe's theory. It is defined crucially in terms of overt material (or wh-traces, see Abe 2015:55, \#40) linearly intervening between two copies forming a chain link. ${ }^{52}$ Because of TP ellipsis, no overt material intervenes between the high and the low copy of ein wie großes Auto'a how big car'. This forces low pronunciation of the chain and, consequently, leads to the deviant sluices in $(122 b-c)$. Again we see that Abe's theory fails to derive the generalization that only $w h$-movable constituents can be sluicing remnants.

We now turn to the question of whether, under Abe's assumptions, there are moving $w h$-phrases that lack the [Focus] markup altogether, (119d). The answer is clearly yes. Abe assumes a very tight syntactic parallelism constraint between antecedent and ellipsis site (this is implicit in the discussion in Abe 2015, p. 21, opening Chap. 2.3 and on p. 40 above \#38). A simple example of sluicing like (124) will thus have the representation indicated.

Somebody was wondering what Joe had brought, but I can't remember who.

... [CP $<$ who $>$ [Focus] $\mathrm{C}_{\mathrm{Q}}\left[\mathrm{TP}[\right.$ Delete $]<$ who $>{ }_{[\text {Focus }][\mathrm{PF}]}^{2}$ was wondering $<$ what $>$ Joe had brought $<$ what $>$ ]]

The important point about the representation is that the wh-phrase what does not and must not carry the [Focus] markup. If it could (or had to) it would be possible (necessary) to pronounce it, counter to fact. Thus, wh-phrases without the [Focus] markup are possible even within the ellipsis site. We saw before that phrases carrying the [Focus] markup may but need not move. (124) shows that moving phrase may be but need not be marked as [Focus]: [Focus] markup is doubly dissociated from movement.

Continuing on to the configuration in (119e), we note that Abe (2015:Chap. 3.4) treats fragment answers as the non-wh-equivalent of sluicing, assigning the following representation to the relevant examples:

$$
\begin{array}{ll}
\text { A: Who did she see? } \\
\text { B: John. } \\
\\
\quad[\text { TP[Delete }] \text { She saw John }[\text { Focus }]
\end{array}
$$

\footnotetext{
${ }^{52}$ I should note that defining PF-effect in terms of crossing rather than overall output is not an accidental flaw in Abe's set of definitions but a (necessary) design feature. Abe's analysis of the swamp construction, (26), rests on the assumption that the pronunciation of this structure will be a picture of who( $m$ ) I don't know rather than a picture of I don't know who $(\mathrm{m})$. This is guaranteed by the idea that high pronunciation of who has no effect on PF output, but such a conclusion can only be drawn if PF output effects are calculated in terms of material crossed by individual chain links rather than in a global fashion.
} 
The ellipsis remnant is marked as [Focus] (in the absence of a wh-phrase) and survives ellipsis. The discussion up to this point thus shows that [Focus] is doubly dissociated from the wh-property: each can appear freely with or without the other. Note again that Abe assumes (crucially in 2015:22, fn. 15) that the remnant in fragment answers may remain in situ. Abe's analysis of fragments thus confirms again that [Focus] markup is independent of movement.

Given this conclusion, one might wonder what is predicted to happen when an elliptical $w h$-question contains focus markup on a phrase which neither dominates nor is dominated by the moving wh-phrase, (119f). It seems that Abe's analysis predicts two different scenarios depending on the exact position of the [Focus] marked phrase. A simple case is the following, which, under Abe's assumptions, allows the full version, (126a), and the elliptical structure, (126b), with the analysis indicated:

a. It is clear who saw the girl, but it is not clear who saw the boy.

b. *It is clear who saw the girl, but it is not clear the boy.

$\left[\mathrm{CP}<\mathrm{who}>^{1} \mathrm{C}_{\mathrm{Q}} \text { [TP[Delete] } \quad<\text { who }>\mathrm{PPF}^{2} \text { saw [the boy }\right]_{[\text {Focus }]}$ f]

The TP is deleted. The $w h$-chain cannot be pronounced high because no pronounced material is crossed. The boy is the sole ellipsis remnant. Similarly, the following example has the derivation indicated in Abe's system:

$$
\begin{aligned}
& \text { *It is clear who the girl saw but it is not clear who the boy. } \\
& {\left[\mathrm{CP}<w h 0>[\mathrm{PF}] \mathrm{C}_{\mathrm{Q}}\right. \text { [TP[Delete] }} \\
& \text { [the boy }]_{[\text {Focus }]}
\end{aligned}
$$

Here TP is deleted to the exclusion of the focus-marked constituent the boy. Crossing of pronounced material leads to high pronunciation of the wh-chain, outside of the ellipsis site. We see that under Abe's theory, sluicing remnants can be phrases that have nothing to do with the $w h$-feature or $w h$-movement, showing just how mistaken Abe's assertion that we quoted above is.

Two important conclusions emerge from this discussion. First, Abe's theory does not come close to capturing anything resembling the generalization that only whmovable constituents can be sluicing remnants, leaving Ross's main argument for a wh-move-and-delete approach to sluicing unaddressed. Second, the [Focus] markup that drives pronunciation within the ellipsis site is doubly dissociated both from movement to the left periphery and from the $w h$-feature.

It is necessary to expand the discussion briefly to chapter 4 of Abe's book, because the conclusion that Abe's [Focus] is doubly dissociated from both movement and wh-features might seem contentious in light of Abe's own discussion in that chapter. Recall that Abe proposes a derivation of the swamp construction in terms of regular $w h$-movement with low pronunciation of the $w h$-phrase coupled with topicalization of the larger containing phrase (see structure (26)). Abe proposes that both wh-movement and topicalization fall within the same movement type (see fn. 11 for discussion). This movement is driven by a feature named [Focus]. ${ }^{53}$ Abe remarks (2015:52-53, fn. 3) that this choice of name for the feature is ultimately arbitrary,

53 "Both a wh-phrase and a topicalized phrase carry [Focus] features and the former is licensed in Spec-CP, whereas the latter is licensed in the Spec of a functional category (call it Topic) higher than CP.[footnote omitted]" (Abe 2015:52, \#33). 
noting that it could have been named $\left[\mathrm{A}^{\prime}\right]$ or [Operator] instead. While this is true, calling the feature driving movement to the left periphery [Focus] is extremely unfortunate in the context of a system where there already is a feature called [Focus],

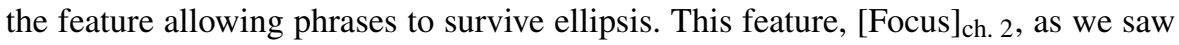

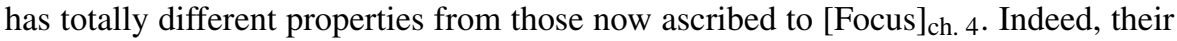
properties are mutually incompatible. [Focus $]_{\mathrm{ch} .4}$ is a feature driving movement to the left periphery; it is inherently present on wh-phrases and fronted topics. As we saw, [Focus $]_{\text {ch. } 2}$ is doubly dissociated from movement and doubly dissociated from $w h$-features. Abe makes no attempt to distinguish [Focus $]_{\text {ch. } 2}$ from [Focus $]_{\text {ch. } 4}$ terminologically and seems to be oblivious to the fact that their content is as different as can be. As far as I can tell, introducing a new [Focus] feature in chapter 4 is terminologically very confusing but does not threaten the conclusion from the above discussion in any way: Abe's theory fails to derive the generalization that only those phrases that can appear in Spec,CP in full wh-questions can appear as remnants in sluicing.

I will conclude by highlighting an interesting question raised by Abe concerning the island sensitivity of the swamp construction. Abe provides the following examples to show that the swamp construction shows island sensitivity (judgments as reported by Abe):

a. ?John denied that he took a picture of somebody, but a picture of whom I don't know. (Abe 2015:48, ex. (10))

b. ?*John met a person who took a picture of somebody, but a picture of whom I don't know. (Abe 2015:48, ex. (11a))

c. ?*John got mad because Mary took a picture of somebody, but a picture of whom I don't know. (Abe 2015:48, ex. (12a))

d. A: John met a person who took a picture of somebody.

B: Oh, (?*a picture of) who? (Abe 2015:50, ex. (23))

e. A: We all complained about the person who spent the entire day doing something at the mall.

B: Oh, (?*doing) what? (Abe 2015:50, ex. (24))

Abe further gives the following examples intended to show that topicalization of the remnant rather than topicalization of the sluice is at play even when there is no exceptional massive pied-piping (judgments as reported by Abe):

a. ?*John met a person who took a picture of somebody, but who I don't know. (Abe 2015:49, ex. (17a))

b. ?*John got mad because Mary took a picture of somebody, but who I don't know. (Abe 2015:49, ex. (17b))

I have not been able to replicate the judgments reported in (128) and (129) with my own informants, who find characteristic island amelioration effects in both. The data are thus somewhat uncertain. I should also note that it is unclear to me how Abe's theory accounts for the judgments he reports for (129). As far as I can tell, nothing in his account rules out a derivation of (129) with a sluice (CP) undergoing topicalization and with island repair within the sluice: 
... but $\left[\left[\mathrm{CP}<\right.\right.$ who $>_{[\text {Focus }]}\left[\mathrm{C}_{\mathrm{Q}}\left[\mathrm{TP}_{\text {[Delete] }}\right.\right.$ John met a persen who toek a pieture of $<$ who $>$ [PF][Focus] $f]]$ I don't know $\left.t_{\mathrm{CP}}\right]$

In other words, it seems to me that Abe's theory predicts (129) to be ambiguous between a structure where the remnant topicalizes and one where the sluice topicalizes (while (128) unambiguously involves the former). The examples in (129) are therefore expected to show the island insensitivity characteristic of sluicing. In other words, the judgments reported by Abe are both subject to unexplained variation and neither of the reported idiolects supports his theory.

Overall, we have seen that Abe's in-situ approach to sluicing fails to capture the generalization that only $w h$-movable categories can be sluicing remnants. The in-situ approach thus fails to pose a serious challenge to $w h$-move-and-delete accounts.

\section{References}

Abe, Jun. 2015. The in-situ approach to sluicing. Vol. 222 of Linguistik aktuell. Amsterdam: Benjamins. Abels, Klaus. 2012. Phases: An essay on cyclicity in syntax. Linguistische arbeiten. Berlin: de Gruyter. Abels, Klaus. 2017a. On the interaction of P-stranding and sluicing in Bulgarian. In Aspects of Slavic linguistics: Formal grammar, lexicon and communication, eds. Olav Mueller-Reichau and Marcel Guhl. Vol. 16 of Language, context and cognition, 1-28. Berlin: De Gruyter Mouton.

Abels, Klaus. 2017b. A partial analysis of "Topicalized Sluicing". Talk presented at Ehrenkolloquium für Gerhild Zybatow, Leipzig.

Abels, Klaus. 2018. Movement and islands. In The Oxford handbook of ellipsis, eds. Jeroen van Craenenbroeck and Tanja Temmerman. Oxford: Oxford University Press.

Abels, Klaus, and Veneeta Dayal. 2017. On the syntax of multiple sluicing. In North East Linguistic Society (NELS) 47, eds. Andrew Lamont and Katerina A. Tetzloff, 1-21. Amherst: GLSA.

Abrusán, Márta. 2014. Weak island semantics. Vol. 3 of Oxford studies in semantics and pragmatics. Oxford: Oxford University Press.

Adger, David, and Josep Quer. 2001. The syntax and semantics of unselected embedded questions. Language 77 (1): 107-133.

Aelbrecht, Lobke. 2010. The syntactic licensing of ellipsis. Amsterdam: Benjamins.

Albukhari, Juman. 2016. The syntax of elliptical constructions in Jordanian Arabic. PhD diss., The University of Wisconsin, Milwaukee.

Algryani, Ali. 2010. Preposition stranding in Libyan Arabic sluicing. Newcastle Working Papers in Linguistics 16: 1-22.

Algryani, Ali. 2012. Sluicing, VP ellipsis and stripping in Libyan Arabic. PhD diss., Newcastle University.

Alrenga, Peter. 2005. A sentential subject asymmetry in English and its implications for complement selection. Syntax 8 (3): 175-207.

Alshaalan, Yara. 2015. Examining the P-Stranding Effect in Saudi Arabic Sluicing. Ms., King Saud University.

Alshaalan, Yara, and Klaus Abels. 2018. On apparent preposition stranding under sluicing in Saudi Arabic. Ms., UCL.

Altmann, Hans. 1981. Formen der »Herausstellung im Deutschen: Rechtsversetzung, Linksversetzung, freies Thema und verwandte Konstruktionen. Linguistische Arbeiten 106. Tübingen: Max Niemeyer Verlag.

Anagnostopoulou, Elena. 1997. Clitic left dislocation and contrastive left dislocation. In Materials on left dislocation, eds. Elena Anagnostopoulou, Henk C. van Riemsdijk, and Frans Zwarts. Vol. 14 of Linguistik aktuell, 151-192. Amsterdam: Benjamins.

Baerman, Matthew, Dunstan Brown, and Greville G. Corbett. 2009. Surrey cross-linguistic database on defectiveness. Available at http://www.smg.surrey.ac.uk/defectiveness/cross-linguistic/. Accessed 31 May 2017.

Barros, Matthew, Patrick D. Elliott, and Gary Thoms. 2013. More variation in island repair: Clausal vs. non-clausal islands. Chicago Linguistics Society (CLS) 49. 
Barros, Matthew, Patrick D. Elliott, and Gary Thoms. 2014. There is no island repair. Ms., Rutgers, UCL, University of Edinburgh.

Bechhofer, Robin. 1976. Reduced wh-questions. In Harvard studies in syntax and semantics, eds. Jorge Hankamer and Judith L. Aissen. Vol. 2, 31-67.

Bianchi, Valentina, and Mara Frascarelli. 2010. Is topic a root phenomenon. Iberia 2 (1): 43-88.

Boone, Enrico. 2015. The syntax and licensing of gapping and fragments. PhD diss., Leiden University.

Bošković, Željko. 2011. Rescue by PF deletion, Traces as (non)interveners, and the that-Trace effect. Linguistic Inquiry 42 (1): 1-44.

Bresnan, Joan W. 2001. Lexical-functional syntax. Oxford: Blackwell.

Cable, Seth. 2007. The grammar of Q: Q-particles and the nature of wh-fronting, as revealed by the whquestions of Tlingit. PhD diss., Cambridge, MIT.

Cable, Seth. 2010. The grammar of Q: Q-particles, Wh-Movement and Pied-Piping. Oxford: Oxford University Press.

Chomsky, Noam. 1972. Some empirical issues in the theory of transformational grammar. In The goals of linguistic theory, ed. Stanley Peters, 63-130. Englewood Cliffs: Prentice-Hall.

Chung, Sandra, William A. Ladusaw, and James McCloskey. 1995. Sluicing and logical form. Natural Language Semantics 3: 239-282.

Collins, Chris. 2015. Relative clause deletion. In 50 years later: Reflections on Chomsky's Aspects, eds. Ángel J. Gallego and Dennis Ott, 57-70. Cambridge: MITWPL.

Culicover, Peter W., and Ray S. Jackendoff. 2005. Simpler syntax. Oxford: Oxford University Press.

Dayal, Veneeta, and Roger Schwarzschild. 2010. Definite inner antecedents and wh-correlates in sluicing. In Rutgers working papers in linguistics, eds. Peter Staroverov, Aaron Braver, Daniel Altshuler, Carlos Fasola, and Sarah Murray. Vol. 3, 92-114. Amherst: LGSA.

Elliott, Patrick D. 2012. Sluicing, the left-branch condition and the (un)reality of island amelioration. Term paper, PLIN3202.

Fortin, Catherine. 2007. Indonesian sluicing and verb phrase ellipsis. PhD diss., University of Michigan.

Fox, Danny, and Howard Lasnik. 2003. Successive cyclic movement and island repair: The difference between sluicing and VP ellipsis. Linguistic Inquiry 34 (1): 143-154.

Frey, Werner. 2004. Notes on the syntax and pragmatics of German Left Dislocation. In The syntax and semantics of the left periphery, eds. Horst Lohnstein and Susanne Trissler. Vol. 9 of Interface explorations, 203-233. Berlin: Mouton de Gruyter.

Grebenyova, Lydia. 2006. Multiple Left-Branch Extraction under Sluicing. Ms.

Grewendorf, Günther. 2009. The left clausal periphery: Clitic left-dislocation in Italian and left-dislocation in German. In Dislocated elements in discourse, eds. Benjamin Shaer, Philippa Cook, Werner Frey, and Claudia Maienborn, 49-94. London: Routledge.

Gribanova, Vera, and Emily Manetta. 2016. Ellipsis in wh-in-situ languages: Deriving apparent sluicing in Hindi-Urdu and Uzbek. Linguistic Inquiry 47 (4): 631-668.

Griffiths, James. 2015. Parenthetical verb constructions, fragment answers, and constituent modification. Natural Language and Linguistic Theory 33: 191-229.

Griffiths, James, and Anikó Lipták. 2014. Contrast and island-sensitivity in clausal ellipsis. Syntax 17 (2): 189-234.

Haider, Hubert. 2010. The syntax of German. Cambridge syntax guides. Cambridge: Cambridge University Press.

Hankamer, Jorge. 1971. Constraints on deletion in syntax. PhD diss., Yale.

Hankamer, Jorge. 1977. Multiple analyses. In Mechanisms of syntactic chains, ed. Charles N. Li, 583-607 Austin: University of Texas Press.

Hartman, Jeremy. 2005. Sluicing in Finnish. Ms., Harvard University.

Hartman, Jeremy. 2007. Focus, deletion, and identity: Investigations of ellipsis in English. BA thesis, Harvard University, Cambridge.

Hartman, Jeremy, and Ruixi Ressey Ai. 2009. A focus account of swiping. In Selected papers from the 2006 Cyprus syntaxfest, eds. Kleanthes Kostas Grohmann and E. Phoevos Panagiotidis, 92-122. Newcastle: Cambridge Scholars.

Hasegawa, Hiroshi. 2006. On swiping. English Linguistics 23 (2): 433-445.

Heck, Fabian. 2008. On pied-piping : Wh-movement and beyond. Vol. 98 of Studies in generative grammar. Berlin: Mouton de Gruyter.

Hooper, Joan B., and Sandra A. Thompson. 1973. On the applicability of root transformations. Linguistic Inquiry 4: 465-497. 
Hornstein, Norbert, Howard Lasnik, and Juan Uriagereka. 2007. The dynamics of islands: Speculations on the locality of movement. Linguistic Analysis 33: 149-175.

Johnson, Kyle. 2001. What VP ellipsis can do, and what it can't, but now why. In The handbook of syntactic theory, eds. Mark Baltin and Chris Collins, 439-480. Oxford: Blackwell.

Kennedy, Chris. 2002. Comparative deletion and optimality in syntax. Natural Language and Linguistic Theory 20 (3): 553-621.

Kennedy, Christopher. 2003. Ellipsis and syntactic representation. In The interfaces: Deriving and interpreting omitted structures, eds. Kerstin Schwabe and Susanne Winkler, 29-53. Amsterdam: Benjamins.

Kennedy, Christopher, and Jason Merchant. 2000. Attributive comparative deletion. Natural Language and Linguistic Theory 18 (1): 89-146.

Kim, Jeong-Seok. 1997. Syntactic focus movement and ellipsis: a minimalist approach. PhD diss., University of Connecticut, Storrs.

Kim, Jong-Bok. 2015. Syntactic and semantic identity in Korean sluicing: A direct interpretation approach. Lingua 166: 260-293.

Koster, Jan. 1978. Why subject sentences don't exist. In Recent transformational studies in European languages, ed. Samuel J. Keyser, 53-64. Cambridge: MIT Press.

Kotek, Hadas. 2015. Covert partial wh-movement and the nature of derivations. Ms., McGill.

Kotek, Hadas, and Michael Yoshitaka Erlewine. 2016. Covert pied-piping in English multiple Whquestions. Linguistic Inquiry 47 (4): 669-693.

Lakoff, George. 1970. Global rules. Language 46: 627-639.

Larson, Richard K. 2014. On shell structure. New York: Routledge.

Lasnik, Howard. 2001. When can you save a structure by destroying it? In North East Linguistic Society (NELS) 31, eds. Minjoo Kim and Uri Strauss, 301-320. Georgetown University: GLSA.

Lasnik, Howard. 2005. The syntax of silence. Language 81 (1): 259-265.

Lasnik, Howard. 2014. Multiple sluicing in English? Syntax 17 (1): 1-20.

Leung, Chun-Wai. 2014. Is Cantonese sluicing just like Mandarin sluicing?: A pseudosluicing approach. Term paper, UCL.

Levin, Lori. 1982. Sluicing: A lexical interpretation procedure. In The mental representation of grammatical relations, ed. Joan Bresnan, 590-654. Cambridge: MIT Press.

Lobeck, Anne. 1995. Ellipsis: Functional heads, licensing and identification. New York: Oxford University Press.

Manetta, Emily. 2013. Copy theory in wh-in-situ languages: Sluicing in Hindi-Urdu. Journal of South Asian Linguistics 6: 3-24.

McCloskey, James. 2006. Questioning and questions in a local English. In Crosslinguistic research in syntax and semantics: Negation, tense, and clausal architecture, eds. Raffaella Zanuttini, Héctor Campos, Elena Herburger, and Paul H. Portner, 87-126. Washington, DC: Georgetown University Press.

Merchant, Jason. 2001. The syntax of silence: Sluicing, islands, and the theory of ellipsis. Oxford: Oxford University Press.

Merchant, Jason. 2002. Swiping in germanic. In Studies in comparative Germanic syntax, eds. JanWouter C. Zwart and Werner Abraham, 295-321. Amsterdam: Benjamins.

Merchant, Jason. 2004. Fragments and ellipsis. Linguistics and Philosophy 27 (6): 661-738.

Merchant, Jason. 2008. Variable island repair under ellipsis. In Topics in ellipsis, ed. Kyle Johnson, 132153. Cambridge, United Kingdom: Cambridge University Press.

Molimpakis, Emilia. 2016. Preposition stranding under sluicing in Modern Greek. Upgrade paper.

Montali, Emanuele. 2014. Sluicing and adjectives. Term paper, UCL.

Moulton, Keir. 2015. CPs: Copies and compositionality. Linguistic Inquiry 46 (2): 305-342.

Müller, Gereon. 1998. Incomplete category fronting: A derivational approach to remnant movement in German. Dordrecht: Kluwer Academic Publishers.

Müller, Gereon. 2011. Constraints on displacement: A phase-based approach. Vol. 7 of Language faculty and beyond. Amsterdam: Benjamins.

Nykiel, Joanna. 2013. Clefts and preposition omission under sluicing. Lingua 123: 74-117.

Nykiel, Joanna. 2017. Preposition stranding and ellipsis alternation. English Language and Linguistics 21: $27-45$

Ortega-Santos, Iván, Masaya Yoshida, and Chizuru Nakao. 2014. On ellipsis structures involving a whremnant and a non-wh-remnant simultaneously. Lingua 138: 55-85.

Ott, Dennis. 2014. An ellipsis approach to contrastive left-dislocation. Linguistic Inquiry 45 (2): 269-303. 
Ott, Dennis. 2015. Connectivity in left-dislocation and the composition of the left periphery. Linguistic Variation 15 (2): 225-290.

Ott, Dennis. 2017. VP-fronting: Movement vs. dislocation. Ms., University of Ottawa.

Ott, Dennis, and Mark de Vries. 2016. Right-dislocation as deletion. Natural Language and Linguistic Theory 34 (2): 641-690.

Ott, Dennis, and Volker Struckmeier. 2018. Particles and deletion. Linguistic Inquiry 49 (2): 393-407.

Panitz, Ezekiel. 2017. Argument ellipsis and strong islands. PhD diss., UCL, London.

Philippova, Tatiana. 2014. P-omission under sluicing, [p clitic] and the nature of p-stranding. In ConSOLE 22, eds. Martin Kohlberger, Kate Bellamy, and Eleanor Dutton. Leiden: LUCL.

Radford, Andrew, and Eiichi Iwasaki. 2015. On swiping in English. Natural Language and Linguistic Theory 33: 703-744.

Richards, Norvin. 2001. Movement in language: interactions and architectures. Oxford: Oxford University Press.

Rodrigues, Cilene, Andrew Ira Nevins, and Luis Vicente. 2009. Cleaving the interactions between sluicing and preposition stranding. In Romance languages and linguistic theory 2006: Selected papers from “Going Romance”, eds. W. Leo Wetzels and Danièle Torck, 175-198. Amsterdam: Benjamins.

Ross, John Robert. 1969. Guess who? In Papers from the fifth regional meeting of the Chicago linguistic society, eds. Robert I. Binnick, Alice Davison, Georgia M. Green, and Jerry L. Morgan, 252-286. Chicago: Chicago Linguistic Society, University of Chicago.

Sakamoto, Yuta. 2017. Escape from silent syntax. Phd diss., University of Connecticut, Storrs.

Salzmann, Martin. 2006. Resumptive prolepsis: A study in indirect A'-dependencies. Phd diss., Leiden, Leiden University.

Sato, Yosuke. 2011. P-stranding under sluicing and repair by ellipsis: Why is Indonesian (not) special? Journal of East Asian Linguistics 20: 339-382.

Schneider, Stefan, Julie Glikman, and Mathieu Avanzi, eds. 2015. Parenthetical verbs. Vol. 557 of Linguistische Arbeiten. Berlin: De Gruyter.

Shen, Zheng. 2018. Fragment answers and movement: A superlative argument. Natural Language and Linguistic Theory 36 (1): 309-321.

Sternefeld, Wolfgang. 2001. Partial movement constructions, pied-piping and higher order choice functions. In Audiatur vox sapientiae: A festschrift for Arnim von Stechow, eds. Caroline Féry and Wolfgang Sternefeld. Berlin: Acadamie Verlag.

Stjepanović, Sandra. 2008. P-stranding under Sluicing in a non-P-stranding language? Linguistic Inquiry 39 (1): 179-190.

Stjepanović, Sandra. 2012. Two cases of violation repair under sluicing. In Sluicing: Cross-linguistic perspectives, eds. Jason Merchant and Andrew Simpson. Vol. 38 of Oxford studies in theoretical linguistics, 68-82. Oxford: Oxford University Press.

Szabolcsi, Anna. 2006. Strong vs. weak islands. In The Blackwell companion to syntax, eds. Martin Everaert and Henk van Riemsdijk, Vol. 4. 479-531. Malden: Blackwell Publishers. Chap. 64.

Takahashi, Daiko. 2013. A note on parallelism for elliptic arguments. In Formal Approaches to Japanese Linguistics (FAJL) 6: MIT working papers in linguistics, eds. Kazuko Yatsushiro and Uli Sauerland, 203-213. Cambridge: MITWPL.

Takano, Yuji. 2000. Illicit remnant movement: an argument for feature-driven movement. Linguistic Inquiry 31 (1): 141-156.

Takita, Kensuke. 2018. Antecedent-contained clausal argument ellipsis. Journal of East Asian Linguistics 27 (1): 1-32.

Temmerman, Tanja. 2013. The syntax of Dutch embedded fragment answers: On the PF-theory of islands and the WH/sluicing correlation. Natural Language and Linguistic Theory 31: 235-285.

Thoms, Gary. 2014. Constraints on exceptional movements in ellipsis are only parallelism effects. In North East Linguistic Society (NELS) 43. Amherst: GLSA.

Turnbull-Sailor, Craig. 2007. Syntactic patterns of embedded wh-clauses. Master's thesis, University of Kansas.

van Craenenbroeck, Jeroen. 2010. Invisible last resort: A note on clefts as the underlying source for sluicing. Lingua 120 (7): 1714-1726.

van Riemsdijk, Henk. 1978. A case study in syntactic markedness: The binding nature of prepositional phrases. Lisse: The Peter de Ridder Press.

Vat, Jan. 1981. Left dislocation, connectedness and reconstruction. Groninger Arbeiten Zur Germanistischen Linguistik 20: 80-103. 
Webelhuth, Gert. 1992. Principles and parameters of syntactic saturation. New York: Oxford University Press.

Weir, Andrew. 2014. Fragments and clausal ellipsis. PhD diss., Amherst, University of Massachusetts. Williams, Edwin S. 2016. Clausal Projection and Clausal Movement. Handout of a talk presented at UCL.

Wiltschko, Martina. 1997. Parasitic operators in German left-dislocation. In Materials on left dislocation, eds. Elena Anagnostopoulou, Henk C. van Riemsdijk, and Frans Zwarts. Vol. 14 of Linguistik aktuell, 307-339. Amsterdam: Benjamins.

Wurmbrand, Susi. 2017. Stripping and topless complements. Linguistic Inquiry 48 (2): 241-366. 